\title{
A global count of the extreme poor in 2012: data issues, methodology and initial results
}

\author{
Francisco H. G. Ferreira ${ }^{1}$ - Shaohua Chen ${ }^{1}$ • Andrew Dabalen ${ }^{2}$. \\ Yuri Dikhanov $^{3}$ • Nada Hamadeh ${ }^{3}$. Dean Jolliffe ${ }^{1}$ (D) . Ambar Narayan' . $^{3}$ \\ Espen Beer Prydz ${ }^{1}$ - Ana Revenga ${ }^{2}$ - Prem Sangraula ${ }^{1}$ - Umar Serajuddin ${ }^{3}$. \\ Nobuo Yoshida ${ }^{2}$
}

Received: 17 February 2016 / Accepted: 22 February 2016 / Published online: 5 April 2016

(C) The Author(s) 2016. This article is published with open access at Springerlink.com

\begin{abstract}
The 2014 release of a new set of purchasing power parity (PPP) conversion factors (PPPs) for 2011 has prompted a revision of the World Bank's international poverty line. In revising the line, we have sought to minimize changes to the real purchasing power of the earlier \$1.25 line (in 2005 PPPs), so as to preserve the integrity of the goalposts for international targets such as the Sustainable Development Goals (SDGs) and the World Bank's twin goals - which were set with respect to that line. In particular, the new line was obtained by inflating the same fifteen national poverty lines - originally used by Ravallion et al. (World Bank Econ. Rev. 23(2): 163-184 2009) to construct the \$1.25 line - to 2011 prices in local currency units, and then converting them to US dollars using 2011 PPP conversion factors. With a small approximation, this procedure yields a new international poverty line of $\$ 1.90$ per person per day. In combination with other changes described in the paper, this revision leads to relatively small changes in global poverty incidence for 2011: from $14.5 \%$ using the old method to $14.1 \%$ using the new method. In 2012, the new reference year for the global count, we find $12.7 \%$ of the world's population, or 897 million people, are living in extreme poverty. There are changes in the regional composition of poverty, but they are also relatively small. This paper documents methodological decisions taken in the process of updating both the poverty line and the consumption and income distributions at the country level, including issues of inter-temporal and spatial price adjustments. It also describes various caveats and limitations of the approach taken.
\end{abstract}

Electronic supplementary material The online version of this article

(doi:10.1007/s10888-016-9326-6) contains supplementary material, which is available to authorized users.

Dean Jolliffe

djolliffe@worldbank.org

Francisco H. G. Ferreira

fferreira@worldbank.org

1 Development Economics Research Group, The World Bank, Washington, DC, USA

2 Poverty and Equity Global Practice, The World Bank, Washington, DC, USA

3 Development Economics Data Group, The World Bank, Washington, DC, USA 
Keywords Global poverty · Poverty measurement $\cdot$ Purchasing power parity

\section{Introduction}

The estimated number of people in the world that live in extreme poverty has become an increasingly important (inverse) indicator for measuring development progress. The first Millennium Development Goal (MDG) aimed to halve the share of people living in extreme poverty between 1990 and 2015. In 2013, the World Bank adopted a goal of ending extreme poverty by $2030 .{ }^{1}$ In 2015 , the United Nations adopted a goal of "ending poverty in all its forms" by 2030 among the Sustainable Development Goals (SDGs). ${ }^{2}$ As one of the most prominent indicators of economic development, the level and trends in extreme poverty are therefore a topic of great interest to both policymakers and the public at large.

Despite the strong policy focus on ending extreme poverty globally, its definition and measurement remain challenging endeavors, subject to much debate regarding the most appropriate concepts, methods and data. At the core of this debate is how to compare the standards of living of widely different peoples, consuming vastly different goods and services, all priced in different currencies. One aspect of this question is how to define a common threshold (or poverty line) which represents the same standard of living, across countries and over time, below which a person is considered poor.

Since the early 1990s, the World Bank has monitored global extreme poverty using an international poverty line that was explicitly based upon the national poverty lines of some of the poorest countries in the world. For ease of communication, this international poverty line has always been expressed in US dollars (USD), but when used for measuring poverty, the line is converted into local currencies through purchasing power parity (PPP) exchange rates, in an attempt to ensure that it has the same purchasing power in every country. The specific PPP conversion factors used for this exercise are those for private consumption, which come from the International Comparison Program (ICP).

Over the last few decades, the ICP has at various times collected price data on a large number of goods and services and in a large number of countries, with each assessment providing new information on how price levels compare across countries. Each release of new PPP data has led both to revisions of the international poverty line, and to re-assessments of the relative differences in wellbeing across countries and regions. The first international poverty line that was based on a sample of national poverty lines was set at \$1.01 using 1985 PPPs, by Ravallion et al. (1991 - henceforth RDW) and used in the 1990 World Development Report (World Bank 1990). Chen and Ravallion (2001) later updated this to \$1.08 per day, using the 1993 PPPs. With the release of the 2005 PPPs and a new set of national poverty lines, Ravallion et al. (2009 - henceforth RCS) proposed a new poverty line of $\$ 1.25$ per day, which is the line that has been used by the World Bank to measure poverty since 2009. Each of these updates has also been associated with revisions in the level and geographical composition of global poverty, often in ways that can be jarring and cast into

\footnotetext{
${ }^{1}$ In April 2013, the World Bank Group announced the goal of ending extreme poverty, which it defined specifically as reducing "the percentage of people living with less than $\$ 1.25$ a day [...] to no more than 3 percent globally by 2030." For more details, see: www.worldbank.org/content/dam/Worldbank/document/ WB-goals2013.pdf.

${ }^{2}$ Target 1.1 of the SDGs describes the goal as follows: "By 2030, eradicate extreme poverty for all people everywhere, currently measured as people living on less than $\$ 1.25$ a day." For more details on the SDGs, see: https://sustainabledevelopment.un.org/?menu=1300
} 
doubt the reliability of the global poverty estimates. ${ }^{3}$ The 2011 PPP conversion factors, released by the ICP in 2014, once again led to substantial revisions in relative price levels, the magnitude of which varies widely across countries.

Inevitably, incorporating the new information on relative price levels that is contained in these conversion factors has implications for the measurement of global poverty and, more specifically, for the definition of the international poverty line. In considering how best to update the line to take account of this new information, we have been guided by three central principles. First, international comparisons of living standards should be based on the most recent reliable information on relative price levels, unless there is sufficient reason to suspect that it is less accurate than previous estimates. Second, we have sought to minimize changes to the real value of a poverty line that has become an important component of a system of international goals and targets, so as to avoid "shifting the goalposts". We have therefore sought to keep the definition of the line unchanged, and its new value as close as possible to that of the $\$ 1.25$ line (in 2005 PPPs) in real terms. Third, when defining "real terms", we have focused on the price levels that matter most for measuring global poverty, namely those faced by the world's poorest countries.

This paper provides a new set of global poverty estimates from 1990 to 2012, using the 2011 PPPs and an international poverty line that was revised in accordance with these three principles. The new value of the international poverty line in USD is \$1.90 in 2011 PPPs. This value is obtained by taking the average value in USD of the same fifteen national poverty lines that RCS (2009) used to estimate the $\$ 1.25$ poverty in 2005 PPPs, after those lines have been inflated to 2011 prices in local currency units, and then converted to dollars using 2011 PPP conversion factors. ${ }^{4}$ By construction, therefore, this $\$ 1.90$ line maintains, on average, the purchasing power of the national poverty lines from these 15 very poor countries. For robustness, we also show that $\$ 1.90$ in 2011 PPPs is the simple average of $\$ 1.25$ in 2005 PPPs (adjusting for domestic inflation between 2005 and 2011) when evaluated over the entire set of 101 countries in which we measure extreme poverty (and which also participated in both the 2005 and 2011 ICP rounds). This finding is the basis for our assertion that the $\$ 1.90$ line maintains the purchasing power of the $\$ 1.25$ line for poor countries more generally.

The new estimates suggest that 897 million people, or $12.7 \%$ of the world's population, live below the international poverty line in 2012 . The level of poverty using the new line and PPPs is similar to estimates based on the 2005 PPPs and the $\$ 1.25$ line. This is best seen comparing the estimates for 2011, a year for which we have numbers from both the old and the new methods: the $\$ 1.25$ line (and 2005 PPPs) yielded a global poverty rate of $14.5 \%$, compared to $14.1 \%$ under the new line and method. The regional distribution of poverty also remains largely unchanged, with Sub-Saharan Africa being home to both the highest incidence of poverty and to the largest absolute number of poor people. South Asia is the region with the second highest incidence of poverty, followed by East Asia and the Pacific. The achievement of the first MDG of halving global poverty from 1990 to 2015 is maintained, and simple extrapolations confirm the current perception that the goal of ending extreme poverty by 2030 is an ambitious one.

The estimates produced in this paper apply the same methods as Chen and Ravallion (2010) and are based on data from PovcalNet, the database maintained by the World Bank

\footnotetext{
${ }^{3}$ Deaton (2010) is one example of a critique of this approach. See also Reddy and Pogge (2008).

${ }^{4}$ As discussed below, this procedure yields $\$ 1.88$, which we round up to $\$ 1.90$.
} 
for monitoring global poverty in recent years. ${ }^{5}$ The most recent version of PovcalNet contains data from more than eleven hundred surveys covering 133 developing countries, and 21 high-income countries. In addition to household surveys and PPP data, the poverty estimates rely on inter-temporal and spatial price deflators and adjustments, which can have large effects on both the international poverty line and on estimates of poverty rates for individual countries. The paper also documents the methods used for aggregating poverty globally and for the alignment of estimates to a particular reference year.

The remainder of the paper is structured as follows. The next section briefly reviews the literature on global poverty measures, with a particular emphasis on the use of PPP conversion factors and the impact they have had on international poverty measures in the past. Section 3 describes in detail the data and methods used in the latest revision of the global poverty numbers. The fourth section describes how the $\$ 1.25$ line was updated to $\$ 1.90$ based on the 2011 PPPs, and the final section presents the 2012 count and reports on the revised global poverty numbers from 1990 to 2012.

\section{A brief history of global poverty measurement using PPPs}

The precise methods used for measuring global poverty have changed over time, but one guiding principle has endured, namely that the international extreme poverty line should reflect how the world's poorest countries estimate a minimum threshold of living which meets basic needs in their societies. This section describes each of the major revisions to the international poverty line, which are also synthesized in Table 1.

One of the first estimates of internationally comparable poverty measures was conducted by Ahluwalia et al. (1979) who use India's national poverty line $\left(46^{\text {th }}\right.$ percentile of the per capita income distribution) to estimate the world's poverty incidence, using the 1975 PPPs from the ICP. Their estimate was based on consumption and income data from 25 countries. While the global coverage of this estimate was limited, this was the first attempt to measure global poverty with a common absolute poverty line. It also began the practice of measuring international poverty based on national lines, converted at PPPs.

Since the 1990s, the international poverty lines used by the World Bank have been defined on the basis of information from a sample of the national poverty lines used in some of the world's poorest countries. RDW (1991) examine 33 national poverty lines and note that six countries among the poorest in this sample (Bangladesh, Indonesia, Kenya, Morocco, Nepal and Tanzania) were all within one dollar of a poverty line of $\$ 31$ per person per month at 1985 PPPs. The similarities in the value of the national poverty line for these six countries then served as the basis for the original "dollar-a-day" global poverty line. ${ }^{6}$ The resulting global count of the poor for 1985 was 1.1 billion persons based on data for 22 countries (with extrapolation models for an additional 64 countries).

\footnotetext{
${ }^{5}$ PovcalNet is perhaps the most commonly used data tool for estimating global poverty counts. It is an online tool, maintained by the World Bank, which allows analysts to specify parameter values such as the global poverty line, and then estimate the number of poor people in the world based on their assumptions. For more details, see: http://iresearch.worldbank.org/PovcalNet/index.htm.

${ }^{6}$ The national poverty lines for six countries (Indonesia, Bangladesh, Nepal, Kenya, Tanzania, and Morocco) were within one dollar of the $\$ 30.42$ per month line. The Philippines and Pakistan were also close to this value. For the purposes of comparison, India's poverty line was, using 1985 PPP terms, \$23 per month. If the India line had been used, the resulting global poverty line would have been about 76 cents per day, rather than the "dollar-a-day" line that was selected.
} 
Table 1 A history of the World Bank's international poverty lines

\begin{tabular}{|c|c|c|c|c|c|}
\hline & 1979 "India line" & 1990 "Dollar-a-day" & 2001 1.08/day & 2008 1.25/day & 2015 1.90/day \\
\hline Source & $\begin{array}{l}\text { Ahluwalia } \\
\text { et al. (1979) }\end{array}$ & $\begin{array}{l}\text { World Bank } \\
\text { (1990) }\end{array}$ & $\begin{array}{l}\text { Chen and } \\
\text { Ravallion (2001) }\end{array}$ & $\begin{array}{l}\text { RCS } \\
(2009)\end{array}$ & This paper. \\
\hline ICP data & $\begin{array}{l}1975 \text { PPPs, } \\
\text { Kravis } \\
\text { et al. (1978) }\end{array}$ & 1985 PPPs & 1993 PPPs & 2005 PPPs & 2011 PPPs \\
\hline $\begin{array}{l}\text { Poverty } \\
\text { lines used }\end{array}$ & 1 (India) & 8 countries & 10 countries & 15 countries & $\begin{array}{l}15 \text { (same lines } \\
\text { as } 2008)\end{array}$ \\
\hline Method & $\begin{array}{l}\text { India's poverty } \\
\text { line }\left(46^{\text {th }} \text { pctile }\right)\end{array}$ & $\begin{array}{l}\text { Inspection } \\
\text { (rounded) }\end{array}$ & Median & Mean & Mean (rounded) \\
\hline $\begin{array}{l}\text { Poverty line } \\
\text { (ICP base } \\
\text { year USD) }\end{array}$ & $\$ 0.56$ & $\$ 1.01(\$ 1.00)$ & $\$ 1.08$ & $\$ 1.25$ & $\$ 1.88(\$ 1.90)$ \\
\hline $\begin{array}{l}\text { Poverty line } \\
\text { (Constant } \\
1985 \text { USD) }\end{array}$ & $\$ 1.12$ & $\$ 1.01$ & $\$ 0.80$ & $\$ 0.69$ & $\$ 0.91$ \\
\hline $\begin{array}{l}\text { Countries } \\
\text { used in } \\
\text { reference } \\
\text { group }\end{array}$ & India & $\begin{array}{l}\text { Bangladesh, } \\
\text { Indonesia, } \\
\text { Kenya, } \\
\text { Morocco, } \\
\text { Nepal, } \\
\text { Pakistan, } \\
\text { Phillippines, } \\
\text { Tanzania, }\end{array}$ & $\begin{array}{l}\text { Bangladesh, } \\
\text { China, India, } \\
\text { Indonesia, } \\
\text { Tanzania, } \\
\text { Thailand, } \\
\text { Tunisia, Nepal, } \\
\text { Pakistan, } \\
\text { Zambia }\end{array}$ & $\begin{array}{l}\text { Chad, } \\
\text { Ethiopia, } \\
\text { The Gambia, } \\
\text { Ghana, } \\
\text { Guinea-Bissau, } \\
\text { Malawi, Mali, } \\
\text { Mozambique, } \\
\text { Nepal, Niger, } \\
\text { Rwanda, } \\
\text { Sierra Leone, } \\
\text { Tajikistan, } \\
\text { Tanzania, } \\
\text { Uganda }\end{array}$ & Same as 2008 \\
\hline
\end{tabular}

Source: Authors' tabulations, based on Sillers (2015) and own compilation

With new household-survey data and expanding country coverage, global poverty estimates were regularly updated, with some substantial modifications over time. These modifications typically occurred in response to each new ICP price data collection exercise, and the subsequent release of new PPP exchange rates, or conversion factors. The first major revision to the dollar-a-day line came when Chen and Ravallion (2001) updated the line based on the then more recent 1993 PPP data. They re-estimated the global poverty line following the same basic idea of basing the global poverty line on a sub-sample of national poverty lines, but used the median national poverty line from the ten lowest national poverty lines from the RDW sample of national poverty lines. This resulted in a revised global poverty line of $\$ 1.08$ a day in 1993 PPP prices.

After the 1993 PPP data, the ICP did not release a significant update until the 2005 benchmark year. In part due to the very long gap in data updates, the release of the 2005 PPP data had significant implications for both the international poverty line and global poverty 
estimates. In preparing an update that incorporated this change in PPPs, RCS (2009) also compiled a new sample of national poverty lines from 74 countries and used it to re-estimate the international poverty line. They observed a positive association between the value of the poverty line and national per capita consumption for the large majority of countries, but found that the relationship was flat for the fifteen poorest countries in their sample. ${ }^{7}$ The simple average of the national poverty lines for these fifteen countries was $\$ 1.25$ in 2005 PPP terms and this then became the revised global poverty line.

Using this new poverty line and the 2005 PPPs, Chen and Ravallion (2010) found that the number of poor was much larger than had previously been thought. The $\$ 1.08$ poverty line and 1993 PPPs suggested that 1.3 billion people were poor all over the world. However, the new $\$ 1.25$ poverty line at 2005 PPPs resulted in an estimated count of 1.8 billion people who were poor in revised estimates for 1993. Thus, the adoption of the 2005 PPPs along with the revision of the international poverty line to $\$ 1.25$ (as well as other new data), resulted in increasing the estimated number of poor in 1993 by 500 million. ${ }^{8}$

This large revision in the estimated count of poor people coincided with a growing interest in global poverty measures on the part of the international development community, and brought about a vigorous debate on how best to measure global poverty. As one example, Deaton (2010) presents the regional profile of global poverty in 1993 when assessed using the 1985, 1993, and 2005 PPPs and the matching global poverty lines for each benchmark year. He makes a couple of points: First, there is substantial variation in both the regional profile and overall level of poverty depending on which PPP and poverty line are used. Second, the $\$ 1.01$ and $\$ 1.08$ poverty lines combined with their benchmark PPP data produced very similar global poverty counts for 1993 . Deaton essentially argues that the $\$ 1.25$ line and the 2005 PPPs resulted in a higher estimated poverty count primarily because of an upward revision of the value of the international poverty line in poor countries, rather than due to the effect of the 2005 PPPs.

A more general point that arises from Deaton's critique - and which the 2011 revisions we are currently incorporating reinforce - is that global poverty estimates have generally been - and remain - very sensitive to the introduction of new PPP conversion factors. As the ICP changes the way in which it collects and combines price data from different countries, in attempts to construct the best possible multilateral price index, estimates of the relative costs of living across nations can change substantially. To the extent that PPPs are used to compare living standards in poverty measurement, these changes inevitably - and occasionally powerfully - affect poverty estimates.

\subsection{The 2011 PPPs and the global poverty estimates ${ }^{9}$}

In 2014, the ICP released the 2011 PPPs, reflecting some key changes in coverage and methodology. Country coverage of the ICP increased from 146 economies in the 2005 round to 199 economies in the 2011 round. The 2011 PPPs are based on data from these 199

\footnotetext{
${ }^{7}$ More specifically, they used the threshold estimator proposed by Hansen (2002) to identify where there is a break between the flat part and upward sloping part of the bi-variate regression of poverty line on the log of per capita consumption. See Fig. 2 in RCS (2009).

${ }^{8}$ The re-estimation of the poverty line to $\$ 1.25$ in 2005 PPPs by RCS (2009) did not aim to maintain strict comparability with the previous $\$ 1.08$ line at 1993 PPPs. Instead, it aimed to better reflect recent national poverty lines in some of the world's poorest countries.

${ }^{9}$ Parts of this section draw heavily from Jolliffe and Prydz (2015).
} 
economies, which represent $97 \%$ of the world's population and approximately $99 \%$ of the world nominal GDP (in USD using market exchange rates). In addition to improved coverage globally, the 2011 PPPs also increased coverage within countries. In particular, World Bank (2015a) reports that the 2011 ICP saw improved coverage of China: The 2005 PPP data for China are based on collecting data from 11 cities (and surrounding areas), but the 2011 PPP data come from nationwide surveys covering urban and rural areas in all provinces. In terms of methodological changes, the ICP 2011 aimed to improve linkages across regions of the world by introducing a "global core list" of 618 items for all countries to include. ${ }^{10}$

The 2011 PPPs significantly revise relative price levels, particularly between rich and poor countries. In broad strokes, the main difference is that relative prices are substantially lower in developing countries according to the 2011 ICP round. As a result, incomes in PPPadjusted dollars are correspondingly higher in poor countries than previously indicated by the 2005 PPPs. This has fostered a new debate about the relative merits and quality of these two ICP rounds.

Deaton and Aten (2014) argue that the 2011 PPPs are superior to the 2005 PPPs, and in part reverse a bias in the 2005 PPP estimates. The 2005 PPPs are essentially the product of two price indices - one index established purchasing power parity within regions and the other compared across regions. The cross-region index is based on data from a set of 18 socalled "ring" countries in which a distinct commodity list was used to price out goods that were not unique to any particular region. Deaton and Aten argue that the cross-region ring index is the key source of error in the 2005 PPP data, resulting in an overestimation of the relative price levels in Africa, Asia and Western Asia by 20 to $30 \%$. Along similar lines, Inklaar and Rao (2014) re-construct the 2005 PPP index following a similar methodology to that used for the 2011 PPP index and find that this methodological difference in the construction of the PPP factors explains a significant portion of the difference in relative price levels.

Findings from Ravallion (2014) lead to almost the opposite interpretation, suggesting that there are potentially significant concerns about the 2011 PPP data. He argues that the downward drift in prices observed for much of Asia (but not China) is in contrast to what would be expected given the observed rate of economic growth. A part of his interpretation of the data rests on the so-called "dynamic Penn Effect" (Ravallion 2013), which suggests that the ratio of the PPP index to the market exchange rate rises with economic growth. Ravallion offers a hypothesis that over time the bundle of goods used for the PPP index has become more heavily weighted towards internationally traded goods (for which prices exist) and this has led to a downward shift in price levels relative to market exchange rates (conditioning on growth rates).

Bypassing the scholarly debate regarding the quality of the 2011 PPP data, others have carried out quick analyses on how the 2011 PPP data would affect global poverty counts. Immediately after the release of the 2011 PPP data, Dykstra et al. (2014) estimated that in 2010 , the share of people in the developing world living below the $\$ 1.25$ per day poverty line declined from $19.7 \%$ to $8.9 \%$ "overnight". Their approach was to adjust the $\$ 1.25$ poverty line, which is denominated in 2005 USD, to 2011 by using the US inflation rate. This adjustment brings their poverty line to a value of \$1.44 in 2011 USD. This methodology differs significantly from the approach followed by RCS (2009) for setting an international

\footnotetext{
${ }^{10}$ Countries were asked to price as many products as possible from the 618 items in the global core list, provided they were available and not unusual in their economies.
} 
poverty line that reflect the poverty lines of some of the poorest countries in the world. Chandy and Kharas (2014) follow an approach similar in spirit (though different in the details) to the methodology used in RCS and re-estimate the poverty line accounting for changes in local price levels. They provide several candidate estimates of the count of the poor, but hone in on an estimate where the number of poor is about 300 million lower in 2010 as a result of using the 2011 PPP data (rather than the 2005 PPP data).

Jolliffe and Prydz (2015) note that all of the early estimates of global poverty based on the 2011 PPPs had been based on leaving in place an adjustment factor for presumed urban bias in India, China and Indonesia. The parameterization of the adjustment factor was specific to details of the fieldwork of the 2005 PPPs, and needed to be either dropped from the analysis or re-calibrated for the re-design of the 2011 PPP fieldwork.

\section{Data and methodology}

A number of choices regarding data sources and methods must be made in the construction of any global poverty estimates. These decisions typically reflect a mix of theoretical foundations, empirical considerations, and knowledge of country and regional context. The present update of global poverty numbers (for the year 2012) follows closely the methods used by Chen and Ravallion (2010) based on the 2005 PPPs and PovcalNet data. While these estimates have been widely used for the monitoring of the MDGs and World Bank goals, some of the details that underpin them have not always been well understood. This section aims to provide an extensive description of the data, assumptions and methods used, and to highlight their merits and limitations. ${ }^{11}$

\subsection{Individual-level welfare measures from household surveys}

At the core of the World Bank's global poverty measurement is a growing collection of income and consumption distributions, primarily derived from national household survey data. For the present global poverty estimates, the World Bank uses income and consumption distributions from more than eleven hundred surveys covering 133 developing countries. The estimates are based on survey interviews of more than 2 million households, representative of $95 \%$ of the population in the developing world. While there has been a dramatic improvement in the availability of consumption and income data over the past two decades, this improvement in the stock has been accompanied by widening heterogeneity of the surveys in terms of instruments (for example, questionnaires) and methods used by countries to measure household consumption, expenditures and income. This widening heterogeneity poses a new set of challenges including whether the aggregates are comparable across countries.

There are several reasons why this assumption of comparability is challenging, but one key reason is that the surveys underlying the welfare distributions used in PovcalNet are carried out by national statistical offices (NSOs), central banks, or other national agencies, as part of national efforts to monitor poverty and wellbeing. The surveys are therefore not designed for the purpose of international comparisons and global monitoring; they are designed to serve the specific needs and interests of each particular country. Different

\footnotetext{
${ }^{11}$ A less extensive, but more in-depth, discussion of select methods and data used in national and global poverty monitoring is available in Jolliffe et al. (2014).
} 
countries use different concepts, methods and questionnaire designs for estimating household consumption and income, and they frequently change the questionnaires over time. This heterogeneity limits the comparability of estimates between countries, and sometimes even within countries over time.

One issue of comparability is linked to the fact that essentially all countries in the PovcalNet database measure wellbeing (either in the form of consumption or income) at the level of the household. So one decision that needs to be made is how to convert a household level measure into an individual level measure. For many countries, making the wellbeing aggregate comparable across individuals means adjusting for differences in needs between different ages of people, typically based on adult-equivalence scales. It may also mean adjusting for household economies of scale. ${ }^{12}$ The key issue for global poverty measurement is that, strictly speaking, a country that allocates household consumption to individuals within the household on a per capita basis has a consumption measure that is not comparable with a country that allocates consumption to individuals based on adult-equivalence. ${ }^{13}$ To treat all countries the same, all consumption and income measures in PovcalNet are expressed in per capita terms. ${ }^{14}$

Another critical issue is that the measure of consumption includes nonmarket transactions for essentially all countries that use a consumption measure of wellbeing. The most prevalent example of this is in the capture of food consumption data. For food, questionnaires are almost always designed to measure consumption from purchases as well as from own production, gifts, or other sources. Similarly, most of the income measures in PovcalNet are harmonized within regions, at least in terms of concepts. For example, the income measures from the Latin America and Caribbean region, come from the Socioeconomic Database for Latin America and the Caribbean (SEDLAC) which constructs comparable income measures.

There are, however, numerous dimensions in which the underlying welfare measure is not harmonized. One important example of this is the mix of income and consumption data in PovcalNet. Table 2 reveals that approximately $75 \%$ of the countries in the PovcalNet database have data on per capita consumption, while the remaining countries - mostly in Latin America and the Caribbean - have income per capita. Income and consumption measures are neither conceptually nor empirically comparable measures of welfare.

Empirically, these differences manifest themselves in two main ways. The first is that, by definition, zero income is a feasible value, while zero consumption is not a feasible value (someone with zero consumption cannot exist for long). Indeed this difference is observable in the data - there is essentially no mass point in any country with zero consumption, ${ }^{15}$ but many countries that use income data have a significant mass of zero incomes in the data, all of which are treated as being poor. Latin America, in particular, predominantly uses income to measure poverty, and in many countries there are a few percent of the observations that are zero.

The difference between consumption and income can also be due to issues of data quality. It is typically presumed that data quality differs between income and consumption, often

\footnotetext{
${ }^{12}$ For discussion of these issues see, for example, Buhmann et al. (1988) and Lanjouw and Ravallion (1995).

${ }^{13}$ For a description of adult-equivalence adjustments, see James and Schofield (1990).

${ }^{14}$ The adoption of a per capita scale imposes cross-country comparability and is easy to explain. It does not, however, address the deeper issue of what the "best" equivalence scale might be in each country.

${ }^{15}$ Zero consumption values may exist in household survey data, but they are often times treated as nonresponders, non-compliant responders and are frequently deleted from the file.
} 
Table 2 Income and consumption distributions in PovcalNet for global poverty estimates

\begin{tabular}{|c|c|c|c|c|c|c|}
\hline & \multicolumn{3}{|c|}{ All of PovcalNet } & \multicolumn{3}{|c|}{2012 Poverty estimates* } \\
\hline & Micro data & Grouped data & Total & Micro data & Grouped data & Total \\
\hline Income & 399 & 79 & 478 & 31 & 3 & 34 \\
\hline Consumption & 563 & 124 & 687 & 94 & 5 & 99 \\
\hline Total & 962 & 203 & 1,165 & 125 & 8 & 133 \\
\hline
\end{tabular}

*The overview for 2012 shows only one distribution per country. For a few countries where there is no distribution for 2012, but there is data for before and after, two distributions are used to interpolate the 2012 estimate

Source: Authors' tabulations of PovcalNet 2015 data. This does not include distributions from high-income countries available in the Luxembourg Income Study and/or other databases

based on the size and formality of the economy. In very poor countries, with little formal employment and mostly agricultural activities, it can be very difficult for survey respondents to provide reasonable answers to income questions. In contrast, in richer countries where work week patterns are uniform, income might be relatively easy to collect while collecting data on consumption may well suffer bias from respondent fatigue. The "best" concept with which to measure household wellbeing may therefore depend on context - on the nature of the income and consumption flows in each society.

Mexico, for which income is used to measure poverty in PovcalNet, provides a useful example of the difference. PovcalNet includes both income and consumption measures for Mexico for the same years. Figure A1 (in the Online Appendix) compares the cumulative density functions for both income and consumption, and makes it clear that poverty estimates differ between the two measures of wellbeing. Using the older 2005 PPP data and $\$ 1.25$ per day poverty line, the poverty headcount based on income was $3.3 \%$, while the estimate based on consumption is $1 \%$. It is noteworthy that the consumption distribution dominates income over the entire range. But this finding is by no means uniform across countries that collect income and consumption: the relative rankings of the two measures vary substantially across countries.

Indeed, in part because there are few fixed, observable patterns in the relationship between income and consumption, no adjustments are made to income or consumption distributions in PovcalNet. While the issue of zero incomes is not currently a very large percent of the global poverty count, it does have significant implications for poverty projections. Projections are based on increasing the measure of wellbeing over time by some estimated growth rate. If income is used as the measure of wellbeing, a growth rate applied to zero income does not change the income level. Projections by construction will never grow the zero incomes out of poverty. This is particularly relevant when examining poverty projections for Latin America, which predominantly uses income data.

In addition to the difference in whether income or consumption is used as the measure of welfare, there is also heterogeneity (both over countries, and over time within countries) in other aspects of how the measures are defined. For example, for most countries in PovcalNet, consumption includes an estimated rental value for housing (for all dwellings whether owned, rented or otherwise used by the household). But this estimated or imputed rental value is not included for all countries, nor is it estimated in an identical fashion for each country for which it is reported, typically owing to questionnaire differences. 
Similarly, there is variation in whether the consumption aggregate includes an estimate of the "use-value" of durable goods (ie. an estimated rental value of the stock of durable goods owned by the household); and for aggregates that do include this estimated use-value, there is significant variation in the expansiveness of the list of household durables. There is also variation in the definition of the welfare aggregate in other items, for example, whether the consumption of health services or education is included.

In addition to heterogeneity in how the welfare aggregate is defined, there is also significant variation in how data is captured (even when the definitions are the same). Research in data collection methods has established that factors such as the length of the recall period and the number of food items in a questionnaire has a large effect on the resulting measure of estimated food consumption. One prominent example of differences in recall periods having large effects on measured poverty is described by Deaton and Kozel (2005a). The India National Sample Survey Organization (NSSO), which had historically used a uniform 30-day recall period (URP), changed recall periods during the 1990s, which resulted in significantly divergent estimates of poverty. After the change in recall periods, reported food expenditures increased by about a third and total expenditure increased by about $17 \%$, thereby considerably reducing poverty estimates.

The World Bank's global poverty estimates for 2012 continue to use the uniform 30day recall period in the headline estimates for India, but also report on the difference in the poverty count when using a modified mixed recall period (MMRP). ${ }^{16}$ The MMRP contains a shorter, 7-day recall period for a subset of food items, which leads to much higher estimates of consumption and therefore lower poverty estimates. For 2011, the estimates based on the URP suggest a poverty estimate of $21.2 \%$, while the MMRP suggests significantly lower poverty rate at $12.4 \%$, which is a difference of more than 100 million people being moved in or out of the current poverty count, depending on the recall period in a single country's survey.

In the case of India, the change in the recall period creates a challenge for making comparisons over time. But the challenge is not limited to India alone, nor just to changing questionnaires over time. Smith et al. (2014) assess recent questionnaires for national household surveys from 100 countries, and focus on how data on food consumption is collected. They document large variation in all dimensions of survey implementation from mode of collection, duration of fieldwork, to coverage of food items. They report, for example, that $30 \%$ of the countries have a recall period for food consumed that is greater than two weeks, while $41 \%$ have recall periods of less than a week.

Such differences in household survey questionnaires over time (and between countries) result in limited comparability in consumption and absolute poverty levels (see, e.g., Beegle et al. 2012, and Jolliffe 2001). This is true whether the differences is in how the survey is administered (for example, diary or enumerated), the extensiveness of the survey (short but comprehensive list of items compared to long list of items), the recall period (for example, 7-day compared to 14-day), or time of interview (for example, whether in the lean or harvest season). For more discussion on this point, and the importance of data quality in general, see Bamberger et al. (2006), Biemer and Lyberg (2003), and United Nations Statistics Division (2005).

\footnotetext{
${ }^{16}$ From 2009, a "modified mixed reference period" (MMRP) was introduced, in which a 30-day recall period was changed to a 7-day recall for key food items, and a one-year recall period for low-frequency non-food consumption items.
} 
Finally, although all the distributions in PovcalNet originate from household surveys, PovcalNet's estimation does not always use this microdata directly. In cases where microdata are not available, PovcalNet uses grouped data (such as quintile or decile shares) and poverty is estimated using a parameterized Lorenz curve. ${ }^{17}$ Although studies have found that such methods based on grouped data do fairly well at estimating poverty at low poverty lines, consistently and without bias, microdata is generally more accurate and ensures consistency with national data sources (Minoiu and Reddy 2009). A strength of the current update is therefore that it relies on a much larger share of microdata for recent poverty estimates (after 1990) than previous versions of PovcalNet: grouped data is now used only for eight of the 133 countries covered. ${ }^{18}$

\subsection{Inter-temporal price adjustments}

Because prices can change rapidly, inter-temporal price deflators are essential for comparisons of real standards of living over time. Since official PPPs are only available for the benchmark years of the ICP, inter-temporal price deflators are necessary to adjust welfare measures for changes in prices between the survey year and the ICP benchmark year. ${ }^{19}$ Similarly, to estimate an international poverty line based on national poverty lines, intertemporal price deflators are used to adjust the value of national lines from various years to the ICP benchmark year, before being converted to PPP-adjusted dollars.

The choice of inter-temporal price deflators can have a considerable impact on estimates of global poverty because it affects both the PPP-adjusted values of income and consumption, as well as the value of the international poverty line. While PovcalNet primarily uses CPI data, it also uses different indices for a few countries, and this choice alone has a substantial impact on the count of poor people.

Table 3 shows that for more than $75 \%$ of the countries, our poverty estimates use the annual official national consumer price index (CPI) reported in WDI to deflate current local (national) currency units (LCU) values from the survey year to constant prices of the ICP base year. ${ }^{20}$ However, in cases where surveys take place in specific months, or where inflation is high, PovcalNet uses monthly CPIs from official sources instead. These series are reported to PovcalNet by World Bank country and regional teams, citing official national sources. For example, from the LAC region, CPIs are primarily monthly series since survey fieldwork is undertaken during specific months of the year. For China and India, PovcalNet uses separate consumption distributions from rural and urban areas and we therefore also use these countries' urban and rural CPIs as deflators. Indonesia also reports separate rural and urban distributions, but no disaggregated deflator is available, so the national CPI is used.

\footnotetext{
${ }^{17}$ In cases where only grouped data is available, PovcalNet bases its poverty estimates on parameterized Beta Lorenz Curve or General Quadratic Lorenz Curve, proposed by Villasenor and Arnold (1989) and Kakwani (1980), respectively. Further details on the computational application and methods used in PovcalNet is documented in Datt (1998). The performance of the methods relative to microdata is reviewed in Minoiu and Reddy (2009).

${ }^{18}$ The countries for which grouped data is used for the 2012 estimate are Algeria, China, Guyana, Iran, Maldives, Trinidad and Tobago, Turkmenistan and St. Lucia.

${ }^{19}$ Alternatively (and equivalently), the international poverty line can be converted to local currency in the ICP base year, and deflated by a temporal deflator to the survey year.

${ }^{20}$ The CPI series reported in World Development Indicators originates from the International Financial Statistics data files from the International Monetary Fund (IMF) and is for period (year) average. This series is also used in WDI to extrapolate PPP conversion factors to years other than the ICP base-year.
} 
Table 3 Temporal price deflators

\begin{tabular}{|c|c|c|}
\hline Deflator type & Source & Countries \\
\hline $\begin{array}{l}\text { Annual National } \\
\text { Consumer Price Index }\end{array}$ & $\begin{array}{l}\text { CPI series (FP.CPI.TOTL) } \\
\text { reported in World Development } \\
\text { Indicators (WDI) - International } \\
\text { Financial Statistics data files }\end{array}$ & 104 countries. \\
\hline $\begin{array}{l}\text { Other National CPIs } \\
\text { (mostly monthly CPIs): }\end{array}$ & $\begin{array}{l}\text { Monthly CPIs from official } \\
\text { sources (National Statistical } \\
\text { Offices or similar) }\end{array}$ & $\begin{array}{l}20 \text { countries, mostly from the } \\
\text { LAC region. }\end{array}$ \\
\hline Sub-national CPIs & From National Official Sources. & $\begin{array}{l}\text { China and India, separate rural } \\
\text { and urban CPI series. }\end{array}$ \\
\hline $\begin{array}{l}\text { Other temporal price } \\
\text { deflators }\end{array}$ & $\begin{array}{l}\text { Various official and non-official } \\
\text { sources }\end{array}$ & $\begin{array}{l}\text { Bangladesh, Cambodia, Ghana*, } \\
\text { Lao, Iraq, Malawi* and Tajikistan*. }\end{array}$ \\
\hline
\end{tabular}

* Indicates countries which also are among the 15 countries that define the international poverty line Note: WDI series is April 2015 version. Sierra Leone had no CPI reported in WDI version used for poverty update and official national series from other source was used

Finally, for a small number of countries, PovcalNet uses alternative inter-temporal deflators estimated from price or unit value data in household surveys or other alternative sources. These are all countries where there is either no CPI data or there are concerns about the accuracy of the data for measuring changing price levels as experienced by poor people. Gimenez and Jolliffe (2014), for example, show a large divergence between CPI data for Bangladesh, survey-based measures of inflation for the poor, and implicit measures of inflation as assessed through official poverty lines. Nevertheless, the decision to deviate from the use of official CPI data is taken very conservatively. For this round, we have taken it only for seven countries and in each case only after detailed consultations with the relevant national statistical bodies and the country poverty economists of the World Bank.

For the 2012 global poverty estimates, such deflators are used in Bangladesh, Cambodia, Ghana, Iraq, Lao, Malawi and Tajikistan. Annex 1 (in the Online Appendix) provides an overview of these countries and the deflators used. For these countries, we have made the assessment that the alternative deflators provided a more accurate picture of changes to prices, particularly to those faced by poor people. As one example of the importance of these differences, in the case of Tajikistan using the official national CPI would imply an $18 \%$ annualized growth of household survey mean from 2004 to 2009, a growth rate that was considered unreasonably high. The alternative inter-temporal deflator used for national poverty measurement implies $6 \%$ annualized growth.

\subsection{Purchasing power parity - updating measures from 2005 PPPs to 2011 PPPs}

Income and consumption measures available from national household surveys, as well as national poverty lines, are denominated in LCUs. To be able to compare the standard of living between countries, one needs to express the measure of consumption or income in common units. One solution would be to use market currency exchange rates to express all values in a common currency, but these exchange rates fail to accurately reflect relative purchasing power, particularly for poorer countries. One reason for this is that non-traded goods, and especially services, are typically cheaper in poorer countries at market exchange 
rates (Balassa 1964; Samuelson 1964). This implies that using market exchange rates to convert consumption or income underestimates the real standard of living in poor countries.

To address this issue, international poverty comparisons use exchange rates based on PPP conversion factors for private consumption from the ICP. These are essentially exchange rates that attempt to adjust for price differences and to ensure that a dollar has the same purchasing power across countries. PPP factors convert the value of consumption from the LCU into a common currency (i.e. USD) in a manner that allows for comparability across countries. PPPs actually enter the international poverty calculations at two stages. First, they are used in constructing an international poverty line based on national poverty lines (converted with PPPs) from some of the poorest countries in the world. Second, to assess poverty in each country, PPPs are used to convert the international poverty line into local currencies or, equivalently, to convert consumption and income distributions from local currencies to PPP dollars, for international comparison.

The PPPs from the 2011 ICP imply some significant revisions to relative price levels between countries, compared to the 2005 ICP. This has important implications for the comparison of real standards of living across the world. To get a better sense of the magnitude of the change in the dollar value of consumption and income by moving from 2005 to 2011 PPPs, it is useful to understand the mechanics of converting values from 2005 PPP-adjusted dollars to 2011 PPP-adjusted dollars.

First note that, by definition, the 2005 PPP conversion factor for a particular country $j$ may be written as the ratio of a certain quantity (e.g. an income level) in that country's local currency units (in 2005 prices - $L C U_{05, j}$ ) to the PPP equivalent in USD (in 2005 prices - IN $\left.C_{P P P 05}\right): P P_{05, j}=L C U_{05, j} / I N C_{P P P 05}$. Analogous identities hold for the PPP conversion factors from other ICP base years, such as 2011. Second, recall that to convert a given income value from 2005 to 2011 prices in local currency units, one uses the domestic inflation rate, $C P I_{11, j} / C P I_{05, j}$. It follows that to convert an income value (from country $j$, from some survey year $t$ ), denominated in 2005 PPP-adjusted USD ( $\left.I N C_{P P P 05, t}\right)$, into 2011 PPP-adjusted USD ( $\left.I N C_{P P P 11, t}\right)$ one writes:

$$
I N C_{P P P 11, t}=I N C_{P P P 05, t} \times \frac{C P I_{11}}{C P I_{05}} \times \frac{P P P 05}{P P P 11}=I N C_{P P P 05, t} \frac{C P I_{11} / C P I_{05}}{P P P 11 / P P P 05}
$$

where $C P I_{11}\left(C P I_{05}\right)$ is the intertemporal price deflator in 2011 (2005), $P P P 05$ $(P P P 11)$ is the 2005 (2011) PPP conversion factor for private consumption, and the country subscript $j$ is omitted for simplicity. Define $\delta$ as:

$$
\delta=\frac{C P I_{11}}{C P I_{05}} \times \frac{P P P 05}{P P P 11}=\frac{C P I_{11} / C P I_{05}}{P P P 11 / P P P 05}
$$

Since the PPPs are measured relative to the price level in the United States in the ICP base year, ${ }^{21}$ the $\delta$ for the US is simply the rate of inflation between 2005 and 2011 (ie. $\delta=1.15$ reflecting US inflation of $15 \%$ ). ${ }^{22}$ Consider a country with $\delta>1.15$, say $\delta=1.20$. To purchase the same amount of goods in that country as could be purchased with one USD in 2005 (converted by 2005 PPP into LCU), one would need $\$ 1.20$ in 2011 (converted by 2011 PPP into LCU). If a poverty threshold had been set at \$1.00 in 2005 PPPs for that particular country, then to ensure that the poverty line purchased the same bundle of goods,

\footnotetext{
${ }^{21}$ More accurately, the global poverty estimates are based on an international poverty line denominated in USD, so the PPPs that are used in the poverty estimation are those that convert LCUs into USD.

${ }^{22}$ This is because in any given year, the PPP for converting a dollar to a dollar is one and therefore PPP05/PPP11 = 1 for the US.
} 


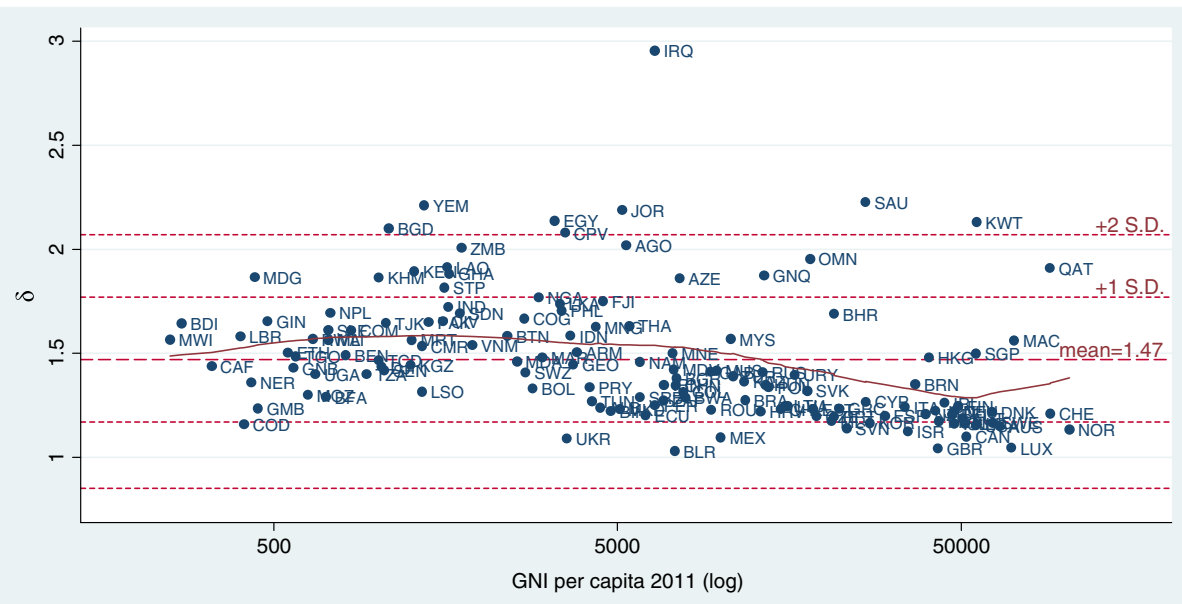

Note: Fitted line uses lowess smoother with bandwith 0.8. Sample limited to countries which participated in both the 2005 and 2011 ICP rounds. $\delta=1$ means no change to the PPP-adjusted dollar value between 2005 and 2011 PPPs.

Fig. 1 Change in PPP-adjusted dollar values between 2005 and 2011 PPPs

it would need to be set at \$1.20 in 2011 PPP terms (i.e. increasing at a rate greater than the US inflation rate). The purchasing power of the local currency is gaining value relative to the purchasing power of a dollar in real terms (accounting for US inflation).

If $\delta$ were 1.15 for all countries, then the overall distribution of wellbeing denominated in USD would not change with the new PPPs. If $\delta$ were greater than 1.15 in most poor countries, they would appear to be getting better off in dollar terms relative to the US. ${ }^{23}$ Between the 2005 and 2011 rounds, $\delta$ does indeed diverge systematically between rich and poor countries. Figure 1 shows $\delta$ for all countries that participated in both the 2005 and 2011 rounds of the ICP, plotted against 2011 GNI per capita. ${ }^{24}$ It shows how poorer countries saw a larger revision $(\delta)$, in comparison to rich ones. ${ }^{25}$ Across all 140 countries for which there exist actual PPP factors in both years, the average $\delta$ is 1.47 , with standard deviation of 0.30 .

When initially reviewing the country-level estimates of extreme poverty based on the 2011 PPP conversion factors, there were several countries with large $\delta$ s, for which the new poverty estimates based on the 2011 PPPs were significantly lower than expected based on the previous estimates for 2011 (using the $\$ 1.25$ line and the 2005 PPPs). A deviation from expectations is certainly not evidence that something is wrong with the $2011 \mathrm{PPP}$ conversion factor. The change could be real, or there could be problems with the CPI data, or with the 2005 PPP conversion factor. However, the countries identified as problematic often had large increases in inflation as measured by the CPI, indicating a decline in purchasing power of the domestic currency, while the ratio of PPPs showed a decline in relative price levels, indicating an increase in purchasing power, relative to the USD.

\footnotetext{
${ }^{23}$ The mean consumption level for the population would increase in dollar terms when evaluated using the 2011 PPPs relative to its value when evaluated using the 2005 PPPs.

${ }^{24}$ We exclude non-benchmark countries (i.e. countries for which regression-based PPPs are reported) in this analysis, as we assume actual PPPs more accurately capture the price levels than imputed PPPs.

${ }^{25}$ This divergence is easiest to observe by looking at rich countries with around 50,000 GNI per capita. There is a large mass of countries with $\delta$ right around one standard deviation below the mean value for the entire sample. It is also useful to note that one standard deviation below the mean is 1.17 , and the US has $\delta$ equal to 1.15 .
} 
Without an explanation for this divergence in price data, and after careful review with country poverty economists, we established a rule that if $\delta$ was more than two standard deviations above the mean, the poverty estimates would not be based on the 2011 PPP data, but would continue to be based on the 2005 PPP data. ${ }^{26}$ There are six such countries, namely Bangladesh, Cabo Verde, Egypt, Iraq, Jordan and Yemen. Countries where $\delta$ is between one and two standard deviations above the mean were examined on a case-by-case basis. For two of them (Cambodia and Lao PDR) the exploratory analysis indicated that the poverty estimates based on 2005 PPPs are more consistent with regional patterns than those suggested by the 2011 PPPs. Therefore, the 2012 poverty estimates for Bangladesh, Cabo Verde, Cambodia, Egypt, Iraq, Jordan, Lao PDR, and Yemen are based on the 2005 PPP data (and \$1.25 line) and not the new 2011 PPP data.

\subsection{Within-country spatial price adjustments}

At any given time, prices vary not only between countries, but also within countries. To compare real standards of living within a country accurately, analysts often make adjustments for spatial (geographic) differences in prices. ${ }^{27}$ Without spatial-price adjustments, a national poverty line could over-estimate poverty in areas with low prices (typically rural areas) and under-estimate poverty in areas with high prices (typically urban areas). To reduce this sort of mis-classification errors, many countries have separate poverty lines for urban and rural areas (or by other sub-national geographies), or adjust consumption and income to account for differences in prices.

For the purposes of the global poverty count, the focus is on obtaining the correct count of poor people in each country; the global count reported by the World Bank typically does not include sub-national estimates of poverty. By design, the data underlying the PPP conversion factors are usually collected from rural and urban outlets and should reflect average national price levels. Similarly, household survey data is sampled from rural and urban areas and by design is nationally representative. ${ }^{28}$ Therefore, for the global poverty count, national PPP conversion factors are generally applied to spatially unadjusted income and consumption distributions, under the assumption that this results in the correct national poverty headcount (and without concern for whether the sub-national profile of poverty is correct). However, there are several important exceptions, for which spatial price adjustments are made to the PPPs or to the income/consumption distributions themselves.

\subsubsection{Rural and Urban PPPs for China, India and Indonesia}

For China, India and Indonesia, we use spatial price adjustments to produce separate rural and urban poverty estimates. These countries are home to a large share of the world's poor,

\footnotetext{
${ }^{26}$ That is if $\delta$ is greater than 2.07. For no countries was $\delta$ more than two standard deviations below the mean. An alternative for assessing outliers that was considered was the extent to which a country's $\delta$ deviates from the ratio of new and old poverty line $(1.90 / 1.25=1.52)$. This way, the identification of outliers would be anchored in the change in the poverty line, rather than the overall change in the PPPs-adjusted dollar value of incomes across all countries. This alternative identified the same countries as problematic.

${ }^{27}$ See chapter 5 in Jolliffe et al. (2014) for an extensive discussion of the importance of spatial price difference in national poverty assessment. Gimenez and Jolliffe (2014) discuss this issue in the context of Bangladesh and Jolliffe (2006) illustrates how the failure to account for spatial difference in prices in the US results in a re-ranking of relative urban-rural poverty rates.

${ }^{28}$ One distinction though is that household survey weights expand to the population of individuals, PPP price data is weighted by the volume of total expenditures in the country.
} 
and their vast geographies may allow for particularly large rural-urban disparities in both prices and living standards. For estimates based on the 2005 PPPs, adjustments to the PPPs for India and China were also motivated by a concern that the 2005 ICP price collection was heavily concentrated in urban areas and that the national PPPs therefore likely had an urban bias (Chen and Ravallion 2010, 2008; Ravallion 2008).

For these three countries, national PPPs from the ICP are disaggregated into rural and urban PPPs that are constructed to reflect cost-of-living differences between rural and urban areas. In backing out separate rural and urban 2011 PPPs for these three countries, we follow steps that are conceptually equivalent to those used by Chen and Ravallion $(2008,2010)$. Specifically, we use rural and urban poverty lines to measure differences in the cost of living, as well as information on the rural and urban shares of the ICP price collection. ${ }^{29}$ The methodology, (see Annex 2 in the Online Appendix) borrowed from Lakner et al. (2015), requires information on urban and rural poverty lines and on the urban share of price outlets. In contrast to the 2005 ICP, in which price collection was concentrated in urban areas, the 2011 ICP saw reportedly better participation in China, with $24 \%$ of the outlets where prices were collected being in rural areas. In India, $25.8 \%$ of locations surveyed were rural in the 2011 ICP, and for Indonesia, $38.7 \%$ of the outlets were in rural areas. Nevertheless, these are large-population countries and accounting for bias, even if small relative to other countries, may be quite important; and the rural-urban unpacking of the PPP is also used to provide separate extreme poverty estimates for rural and urban areas in these countries.

Data on the urban and rural poverty lines come from the national statistical offices of each country or, in some cases, the World Bank's country poverty economists. Since China does not have an official urban poverty line (only a rural line), Chen and Ravallion (2008) use the ratio of national poverty lines computed by China's National Bureau of Statistics (NBS), in collaboration with the World Bank, in 2002/3. For 2005, the line was $37 \%$ higher for urban compared to rural areas. ${ }^{30}$ Based on changes in rural and urban prices for people living close to the poverty line, the urban-rural difference (for the poor) in China in 2011 is now estimated to be $28.5 \%$. To arrive at this number, inflation for the urban poor was calculated using the bottom decile of the urban distribution. In 2011, the Chinese government announced a new rural poverty line, however no comparable urban line is yet available, and so the $28.5 \%$ rural-urban ratio for 2011 is used here. ${ }^{31}$

In the case of India, official rural and urban poverty lines are readily available from national sources. Chen and Ravallion (2010) used the official poverty lines from India's Planning Commission for 2004-05, which suggest cost of living being $51 \%$ higher than

\footnotetext{
${ }^{29}$ Because cost-of-basic-needs poverty lines are typically estimated to include an allowance for nonfood consumption, and this allowance frequently differs across urban and rural areas, differences in poverty lines are more accurately described as reflecting differences in the cost of living, rather than differences in prices: they potentially reflect differences in both prices and quantities. In contrast, the adjustments for LAC and ECA countries, discussed below, are more accurately referred to as spatial-price adjustments.

${ }^{30}$ In addition to cost-of-living differences, this difference also reflects differences in the definition of consumption expenditures in the rural and urban surveys.

${ }^{31}$ Starting in 2013, China's NBS has conducted a unified national household survey, replacing the separate rural and urban surveys conducted in the past. In this context, NBS has also ex-post harmonized the separate rural and urban distributions from the 2011 and 2012 surveys to create unified national distributions that aim to be comparable with the new national survey. Estimates of extreme poverty in China using these ex-post harmonized national distributions for 2011 and 2012 and the un-adjusted (national) 2011 PPPs are similar to those obtained using the original (separate rural/urban) surveys and our PPP adjustments. The harmonized distributions for 2011 and 2012 give national poverty estimates of $8.0 \%$ and $6.0 \%$, respectively, compared to $7.9 \%$ and $6.5 \%$ from the original rural and urban distributions and above adjustment. The World Bank will update China's poverty estimates when integrated and revised surveys become available in the future.
} 
in rural areas. ${ }^{32}$ More recently, an Expert Group constituted by the Government of India (2009) recommended a higher rural poverty line based on corrections for biases in past price deflators. The revised so-called Tendulkar poverty lines for 2011-12, propose an urban line being only $22 \%$ higher than the rural line (Government of India 2013). This is the ratio used in the present estimates for India. For Indonesia, we use the official urban and rural poverty lines from 2011 (Statistics Indonesia 2015). Table A1 (in the Online Appendix) summarizes the data used in applying these adjustments and the resulting rural and urban 2011 PPPs for China, India and Indonesia.

\subsubsection{Within-country spatial price adjustments in LAC and ECA}

The second category of within-country spatial adjustments is pertinent to the Latin America and Caribbean (LAC) region and the Europe and Central Asia (ECA) region. For most countries in these regions, PovcalNet draws on spatially adjusted consumption and income aggregates from regional databases. In LAC, PovcalNet uses aggregates from the Socioeconomic Database for Latin America and the Caribbean (SEDLAC) in which all rural incomes are increased by a factor of $15 \%$ to capture differences in rural-urban prices, based on average rural-urban price differences observed in the region (CEDLAS and World Bank 2010). Although this uniform adjustment is somewhat arbitrary, CEDLAS argues that it is preferable to ignoring the problem of spatial price differences or allowing for different methods across countries. Adjusting all incomes from SEDLAC to urban price level is particularly reasonable in the context of international poverty measurement using PPPs, since the ICP exercise (both in 2005 and 2011) in this region is carried out solely in urban areas and therefore explicitly does not capture rural price levels.

Similar to the LAC region, PovcalNet also draws its consumption and income aggregates in ECA from a regional database, ECAPOV. This regional database, maintained by the World Bank, also embeds spatial-price adjustments into many of its consumption aggregates. ECAPOV adopts, whenever information on households' purchased quantities is available, a spatial Paasche index based on unit values from food consumption, which is then applied to all consumption items (including non-food items). Unlike the LAC region, however these prices are not expressed at the urban level, but adjusted to reflect national prices. ${ }^{33}$ Table A2 (in the Online Appendix) recaps the various spatial price adjustments embodied in PovcalNet data.

From the perspective of comparability, it would be desirable to have more consistent methods to adjust for within-country differences in prices. As one example, the adjustments for rural-urban differences in the cost of living made for China, India and Indonesia differ from those made for other countries, and the overall poverty count is sensitive to the assumptions underlying these adjustments. Jolliffe and Prydz (2015) note that the approach followed for these three countries has the overall effect of lowering the

\footnotetext{
${ }^{32}$ India's official poverty lines for 2004-05 were Rs 17.71 and Rs 11.71 per day for urban and rural areas, giving a ratio of 1.51 in 2005. These lines date back to Government of India (1979) and have since been updated by rural and urban inflation. Update by rural and urban CPIs to 2011 this ratio is 1.45 in 2011.

${ }^{33}$ Another way of stating this is that in ECAPOV, mean consumption levels are not changed when adjusting for spatial differences in prices.
} 
poverty estimates, relative to a benchmark of simply applying the national PPPs to national distributions.

While further research is needed to help identify a more uniform approach to accounting for within-country spatial price differences when estimating global poverty, we believe the approach followed for the 2012 estimates offers two desirable properties. First, this approach allows us to separately estimate the extent of rural poverty in each of these countries, which is useful given the sheer size of their rural populations. Second, and perhaps most importantly, the approach we follow for adjusting the 2011 PPP factors for China, India and Indonesia is the same approach followed by the World Bank for the previous estimates based on the 2005 PPP conversion factors. The only change made is that the ruralurban scaling factors have been updated to reflect more recent data. This approach allows us to continue monitoring progress towards the goal of eliminating extreme poverty using the same yardstick as previously used.

\subsection{Alignment, aggregation and reporting of poverty estimates}

For individual countries, the World Bank publishes (on PovcalNet) poverty numbers based on the international poverty line only for years for which it has household survey data on income or consumption. However, the estimated total count of poor people in the world for 2012 is based on a poverty estimate for all countries in 2012 - that is, poverty in 2012 is estimated for a country even if no household survey data is available from 2012. For example, if a country has data from 2010 , these data are used to project an estimated poverty rate to 2012 for the purposes of the global count. An alternative to projecting the 2010 data forward to 2012 would be to use the poverty count from the actual year the data was collected, but this is viewed as an undesirable option. If the economy of this country had been growing between 2010 and 2012, then the poverty headcount from 2010 would most likely overestimate the poverty headcount in 2012 .

For countries for which there is no survey available in the specific reference year for the global estimate, the country-level poverty count is estimated by extrapolating consumption or income from the latest survey using growth rates from national accounts. This procedure assumes distribution-neutral growth, i.e. no change in inequality. In addition, because growth in survey means has historically been lower than growth observed in national accounts data, the growth rates used for extrapolating the survey data are adjusted for these observed differences. If a survey is available after the reference year, that information is also used: An average of the two extrapolated estimates is then reported, (inversely) weighted by their relative distance from the reference year. The mechanics of the extrapolation and interpolation are described in more detail in Ravallion (2003), Chen and Ravallion (2004) and Jolliffe et al. (2014).

For countries without any poverty estimates, extrapolation to the reference year is of course not an option, and PovcalNet does not report poverty estimates for these countries. Nonetheless, these countries do indirectly enter the regional and global poverty counts. The country-level poverty headcount used to account for them in regional totals is the product of the estimated poverty headcount in the remainder of the region to which they belong (e.g. sub-Saharan Africa) and the country's own population, as reported by the WDI. So, when aggregating to regional and global totals, developing countries without any poverty measures are in effect assigned the average headcount for their regions. This procedure is obviously not intended to suggest any inference about poverty in those specific countries, 
which is why numbers are not reported for them. Rather, it is a compromise intended to avoid undercounting poverty in those regions with weaker data coverage. ${ }^{34}$

High-income countries are assumed to have no people living in extreme poverty in our global count. Although some people in rich countries report household per capita incomes that are below the international poverty line, per capita consumption is above this threshold for nearly everyone. Drawing an example from the United States, Chandy and Smith (2014) find that $1 \%$ to $4 \%$ of the population live below $\$ 2$ a day when using income measures, but that less than $0.1 \%$ live below this threshold when using consumption measures. While the assumption of zero people in extreme consumption poverty may not be fully supported, it is a useful simplifying assumption that appears to closely approximate the correct estimate.

In most cases, our estimate aims to be as complete as possible in terms of coverage; but there are cases where countries and regions are excluded. The World Bank previously reported global poverty numbers in 3-year intervals from 1981 to 2008. Since 2010, there have been annual updates for the reference-year poverty estimates, with this paper presenting estimates for the 2012 reference year. ${ }^{35}$ For each reference year, we calculate a population coverage rate for regional poverty estimates. The coverage rate is defined by the share of the population in each region which is covered by a survey within plus or minus two years of the reference year. In other words, for reference year 2012, if a country has a survey anywhere from 2010 to 2014 , then it is treated as providing coverage for the estimate. If the coverage rate is less than $60 \%$ we do not report the regional poverty estimate. For reference year 2008 and later, the Middle East and North Africa region falls below this threshold and poverty numbers are not reported.

\section{Updating the international poverty line on the basis of the 2011 PPPs}

In April 2013, the World Bank Group announced the goal of ending extreme poverty, which was defined specifically as reducing "the percentage of people living with less than $\$ 1.25$ a day [...] to no more than 3 percent globally by 2030." The introduction of the 2011 PPPs creates a potential measurement challenge for faithfully monitoring progress towards this goal. The \$1.25 line stated in the goal (essentially the target's "goal post") is based on the 2005 PPPs. If 2011 PPPs are used to convert the LCU values of consumption and income distributions, what is the poverty line that most closely reflects the same value as the $\$ 1.25$ line, but is expressed in 2011 PPPs?

Given the importance of avoiding manipulation (and the appearance of manipulation) of the "goal post", by either making the goal harder or easier to reach, one option that was given serious consideration was simply to not adopt the 2011 PPPs and continue to use the $\$ 1.25$ line in 2005 PPP-adjusted USD. But, if the threshold that is used to identify the poor is expressed in the relative price levels as estimated by the 2005 PPP data, then the consumption and income distributions must also continue to be based on the 2005 PPPs. This option was considered and ultimately rejected - a decision that is in line with the majority of scholarly opinion that the 2011 PPPs incorporate a number of improvements

\footnotetext{
${ }^{34}$ For an overview of countries missing poverty data, see Serajuddin et al. (2015).

${ }^{35}$ Reference years used in PovcalNet are 1981, 1984, 1987, 1990, 1993, 1996, 1999, 2002, 2005, 2008, 2010, 2011, 2012.
} 
in terms of coverage and methodology, and therefore provide a more accurate reflection of relative price levels in the world.

With the decision to use the 2011 PPPs then comes the responsibility of revising the \$1.25 line to 2011 PPP terms. Because the 2011 PPPs revise the relative price levels between countries, there exists no adjustment to the $\$ 1.25$ line in 2011 PPPs that would produce the same headcount rate as the 2005 PPPs in each country (at least not if we restrict the revision to maintaining a single line for all countries). Any proposed revision will change the real value of the line in many, if not most, countries. An initial proposal from Dykstra et al. (2014) was to update the line based on US inflation rate. The value of their revised line was $\$ 1.44$. But, as discussed earlier in the paper, relative price levels between rich and poor countries were systematically revised with the 2011 ICP. Therefore, although $\$ 1.44$ would buy the same bundle of goods in the US in 2011 as $\$ 1.25$ did in 2005, the relative shift in prices means that $\$ 1.44$ in 2011 would buy significantly less in most poor countries (i.e, it lowered significantly the real value of the poverty line for most poor countries of the world). The Dykstra et al. line very dramatically changed the goal posts, and not surprisingly, the resulting estimates radically reduced the global poverty count.

Nevertheless, a useful point that came from Dykstra et al. is that it forces one to think about what we mean when we say we want to keep the real value of the $\$ 1.25$ line the same, but express it in 2011 PPPs. Their $\$ 1.44$ line did maintain the real value of the $\$ 1.25$ line, but only for the US (or, more completely, only for countries with the $\delta$ defined in Eq. 2 with values close to 1.15$)$.

In our view, the goal should be to try to find a line that would keep the definition of the line as consistent as possible, and on average buy the same bundle of goods as the $\$ 1.25$ line did, but in poor countries - such as those used to construct the $\$ 1.25$ line. ${ }^{36}$ This approach has some attractive features, including from a communications standpoint. It is relatively easy to state that the definition of the new poverty line is unchanged, and that, on average, it buys the same bundle of goods that could have been purchased in 2005 with $\$ 1.25$ in the fifteen countries that define the international poverty line.

Another desirable attribute is that it is a relatively simple adjustment to make. This decision ensures that the concept (poverty lines of the same 15 poor countries); method (simple average across these same 15 countries); and data (the same 15 national poverty lines) are unchanged. The only element that is changing is the PPPs used to convert the national lines to estimate an international line. Table 4 provides the 2005 and 2011 PPP values of these national poverty lines, as well as the PPPs and CPIs used for the conversion (see, Eq. 1). Taking the average of the same 15 national poverty lines that yielded the $\$ 1.25$ line in 2005 PPPs, now gives $\$ 1.88$ per day in 2011 PPPs, which is rounded to $\$ 1.90$ for ease of communication. Because this average is based on the exact same national lines as the $\$ 1.25$ line, we believe the $\$ 1.90$ line reflects the most comparable benchmark possible for updating the \$1.25 line to 2011 PPPs. Given the nature of the 2011 ICP revision of PPP conversion factors, this is the line that least changes the goalposts, by the standards of the world's poorest countries.

However, using the average of these 15 countries' poverty lines does have potential limitations, in part due to weak statistical support, as reviewed by Jolliffe and Prydz (2016) in this issue. Deaton (2010) similarly critiques this approach, arguing that the average should

\footnotetext{
${ }^{36}$ This approach has risks, in particular if the change in relative prices for those 15 countries is radically different from the change in relative prices for most poor countries but, as we will see, this is not the case for the present update.
} 
Table 4 Re-estimating \$1.25-line using the 2011 PPPs

\begin{tabular}{llrrlll}
\hline Country & $\begin{array}{l}\text { Poverty line } \\
\text { year(s) }\end{array}$ & 2005 PPP & 2011 PPP & $\begin{array}{l}\text { CPI 2011 } \\
(2005=100)\end{array}$ & $\begin{array}{l}\text { Poverty line } \\
2005 \text { PPP }\end{array}$ & $\begin{array}{l}\text { Poverty line } \\
\text { 2011 PPP }\end{array}$ \\
\hline Malawi & $2004-05$ & 56.92 & 78.02 & $214.6^{*}$ & 0.86 & 1.34 \\
Mali & $1988-89$ & 289.68 & 221.87 & 119.8 & 1.38 & 2.15 \\
Ethiopia & $1999-2000$ & 2.75 & 5.44 & 297.1 & 1.35 & 2.03 \\
Sierra Leone & $2003-04$ & 1396.21 & 1767.19 & $203.9^{ \pm}$ & 1.69 & 2.73 \\
Niger & 1993 & 267.33 & 228.75 & 116.3 & 1.10 & 1.49 \\
Uganda & $1993-98$ & 744.62 & 946.89 & 178.0 & 1.27 & 1.77 \\
Gambia, The & 1998 & 10.34 & 10.83 & 129.3 & 1.48 & 1.82 \\
Rwanda & $1999-2001$ & 236.75 & 246.83 & 157.8 & 0.99 & 1.50 \\
Guinea-Bissau & 1991 & 284.28 & 248.24 & 124.8 & 1.51 & 2.16 \\
Tanzania & $2000-01$ & 482.45 & 585.52 & 169.9 & 0.63 & 0.88 \\
Tajikistan & 1999 & 0.93 & 1.88 & $334.2^{*}$ & 1.93 & 3.18 \\
Mozambique & $2002-03$ & 11.63 & 15.53 & 173.5 & 0.97 & 1.26 \\
Chad & $1995-96$ & 327.57 & 251.30 & 112.4 & 0.87 & 1.28 \\
Nepal & $2003-04$ & 26.47 & 25.76 & 164.8 & 0.87 & 1.47 \\
Ghana & $1998-99$ & 0.45 & 0.79 & $295.2^{*}$ & 1.83 & 3.07 \\
Mean & & & & & 1.25 & 1.88 \\
\hline
\end{tabular}

Note: National poverty lines in 2005 PPPs from RCS (2009). Poverty lines in 2011 PPPs are authors' estimates based on CPI data from WDI and PPP data from ICP 2011. ${ }^{ \pm}$WDI has does have sufficient CPI data for Sierra Leone, data consistent with national series used. Countries marked with (*) uses CPI which is different from that reported in WDI. See section on inter-temporal price deflators and Annex 1 for details. RCS (2009) provides lines in monthly amounts which are converted to daily amounts by a factor of 12/365. All the computations in this Table are based on Eq. 1

be weighted by the poor population (where this population is defined by the national poverty line) to better reflect the poverty line faced by the average poor person. Deaton (2010) also criticizes the selection of the 15 countries, which can similarly be interpreted as a critique of the statistical support for the line.

Kakwani and Son (2015) have proposed an alternative approach to calculate a new global poverty line based on 2011 PPPs, using what they call "equivalent poverty lines", which are poverty lines for each country that produce the same poverty headcount in 2011 PPPs, as with 2005 PPPs. In effect, their approach converts the \$1.25 in 2005 PPP-adjusted dollars into 2011 PPP-adjusted dollars for each country. ${ }^{37}$ Because of divergent changes in the CPIs and PPP conversion factors across countries between the 2005 and 2011 rounds, this leads to a wide range of values in 2011 PPPs. To calculate a single poverty line in 2011 PPPs, they propose using the weighted average of the equivalent poverty lines of 66 countries with weights proportional to their populations, giving them a value of $\$ 1.78$ in 2011 PPP. As a robustness check to the $\$ 1.90$ line, we expand on this approach using our own data.

Figure A2 in the Online Appendix shows the "equivalent poverty lines" of the 101 countries in which we measure extreme poverty, and which also participated in both the 2005 and 2011 ICP rounds, plotted against the countries' income levels. Using the "equivalent

\footnotetext{
${ }^{37}$ Conversion of 1.25 from 2005 PPP-adjusted dollars to 2011 PPP-adjusted dollars is simply the product of $\$ 1.25$ and $\delta$ for each country. This way the poverty line is held constant in local currencies.
} 
poverty lines" approach proposed by Kakwani and Son would result in an unweighted average of $\$ 1.90$, and a population weighted average of $\$ 1.93 .{ }^{38}$ Using the "equivalent poverty lines" approach among the 15 countries that originally defined the $\$ 1.25$ line - which would also satisfy the desire of keeping the poverty line "constant" (on average) in the world's poorest countries - would give a simple average of $\$ 1.86$ and a population weighted average of $\$ 1.88$. The fact that all four of these numbers are either equal or very close to $\$ 1.90$ provide additional support for the robustness of our approach, the results of which are largely unaffected by the identity of the original RCS fifteen countries.

Not unexpectedly, given the regional differences in revisions of relative price levels from the 2011 ICP, the average "equivalent poverty lines" diverge regionally. Sub-Saharan Africa's "equivalent poverty lines" give a simple average of $\$ 1.94$, close to the overall mean, while LAC and ECA's poverty equivalent lines are around \$1.60, and EAP, MENA and SAR have averages above \$2. (See Table A3 in the Online Appendix.) This suggests that, on average, a line of $\$ 1.90$ would lead to small changes in countries in Africa, higher poverty in countries in LAC and ECA, while for countries in EAP and SAR poverty would fall with the new PPPs. Of course, the precise changes to the regional aggregates will depend on population shares and the density of the distribution around the poverty lines in these countries, as well as other adjustments.

Another alternative approach to updating the $\$ 1.25$ line would be to re-estimate the relationship between national poverty lines and national incomes from RCS using the 2011 PPPs. Such a procedure could involve selecting a new sample of the poorest countries as the reference group for the international line (see, Jolliffe and Prydz, this issue, and Klasen et al., this issue). Klasen et al. (this issue) suggest re-estimating the poverty line using the original, piecewise regression function similar to that used to identify the reference group of 15 countries that defined the $\$ 1.25$ line. On that basis, they estimate an updated global line of \$1.67-\$1.71. However, Klasen et al.'s poverty line estimates are significantly lower because they rely on CPIs from WDI, which, as discussed in preceding sections, underestimate inflation (and thus the conversion from 2005 to 2011 PPPs) for a number of countries. Alternatively, if we re-rank the RCS sample of poverty lines by mean consumption denominated in 2011 PPPs, one country in the bottom 15 changes - and the mean of the lines in 2011 PPPs becomes $\$ 1.84$. However, across these approaches, the reference group defining the international line changes, and the resulting line would no longer be based on the same 15 countries that produced the $\$ 1.25$ line. ${ }^{39}$

Finally, some observers have argued that the most important aspect of holding the poverty line (or at least the 'goal post') fixed is to keep the poverty headcount fixed when switching from the 2005 to 2011 PPPs. Sillers (2015) proposed a 'continuous headcount' approach in which the global poverty line is updated such that the global headcount is unchanged. His estimate is that the line which would in 2011 keep the global headcount unchanged compared with the $\$ 1.25$ line, would be $\$ 1.78$ per day at 2011 PPP. Sillers' estimation, however, relies on different rural-urban adjustments for China, India and Indonesia, which are updated in the present analysis. When we use the new adjusted 2011 PPPs, and follow the Sillers methodology, preliminary estimates suggest that the line that would keep the global headcount unchanged in 2011 would be around $\$ 1.92$ per day.

\footnotetext{
${ }^{38}$ These estimates differ from Kakwani and Son (2015) due to our larger sample size, and use of different CPIs for selected countries.

${ }^{39}$ See also Jolliffe and Prydz (2015).
} 
All in all, most of the alternative approaches that have been proposed for updating the international poverty line to 2011 PPPs end up generating lines that are either exactly or very close to $\$ 1.90$ a day. We take this as providing reassurance that our approach - deliberately motivated by a concern with preserving the integrity of the goalposts used for the SDGs and the Bank's own twin goals - is in fact reasonably robust.

\section{Results}

This section presents new estimates of global poverty based on the $\$ 1.90$ line and the 2011 PPPs. In presenting the results, we highlight how the new estimates compare to the previous estimates based on the $\$ 1.25$ line and the 2005 PPPs. When considering the comparisons, it is important to note that there are many changing elements in the estimates. In addition to incorporating the new poverty line and the 2011 PPPs, the new results reflect a number of other updates to the data, such as new surveys, increased use of micro-data, changes to welfare aggregates, revised inter-temporal deflators, and updated population figures. While this paper will use the short-hand reference to the 2005 PPP and 2011 PPP poverty estimates, the comparisons will reflect differences in all the elements noted above. For example, the present update includes estimates for five countries for which international poverty estimates have not been available at all in the past, namely Kiribati, Kosovo, Solomon Islands, Tonga and Vanuatu. These simultaneous changes to the data make it impossible to identify from the comparisons reported here, the precise isolated effect of introducing the 2011 PPPs and the $\$ 1.90$ line in our analysis. Additional analysis of recent trends in global poverty, and the outlook for the future, is available in World Bank (2015b) and Cruz et al. (2015).

\subsection{Updated country-level estimates of poverty}

Although the updated poverty line of $\$ 1.90$ in 2011 PPPs reflects the same real standard of living as the $\$ 1.25$ line did in 2005 PPPs (on average across poor countries), the new line and PPPs do of course lead to changes to poverty counts in individual countries. Figure A3 in the Online Appendix illustrates three examples of changes in country-level poverty estimates between the \$1.25 line at 2005 PPPs and the \$1.90 line at 2011 PPPs. For Armenia, the 2011 PPPs resulted in a revision of PPP-adjusted dollar value of consumption that was close to proportional to the change in the poverty line from $\$ 1.25$ to $\$ 1.90$, leading to very minor changes in poverty. ${ }^{40}$ For Botswana, the revision of PPP-adjusted consumption levels was smaller than the revision of the PPP-adjusted value of international poverty line and, as a result, the poverty estimates under the new line are higher. In contrast, for Nepal, the 2011 PPPs implied a revision of the PPP-adjusted welfare aggregates that was significantly higher than the revision of the poverty line, and the resulting poverty estimates using 2011 PPPs is thus lower than the estimates based on 2005 PPPs. It is noteworthy that notwithstanding the changes in levels, across all three countries the trends in poverty between different surveys are broadly maintained. This is as expected since the revision to PPP-adjusted consumption and income is uniform across years.

\footnotetext{
${ }^{40}$ The direction and magnitude of the changes can also be assessed in terms of the difference between the 1.90 line and the "poverty equivalent" lines discussed in the preceding section. The poverty equivalent line in for Armenia was $\$ 1.88$ - close to the $\$ 1.90$ poverty line. The poverty equivalent lines for Botswana and Nepal are $\$ 1.61$ and $\$ 2.11$, respectively.
} 
Panel A

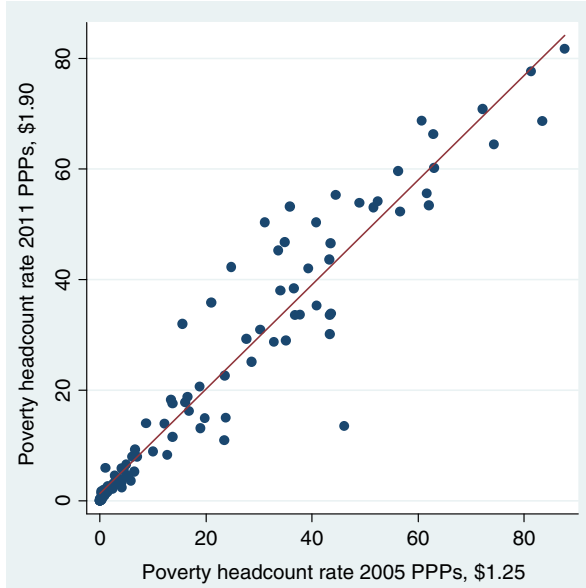

Panel B

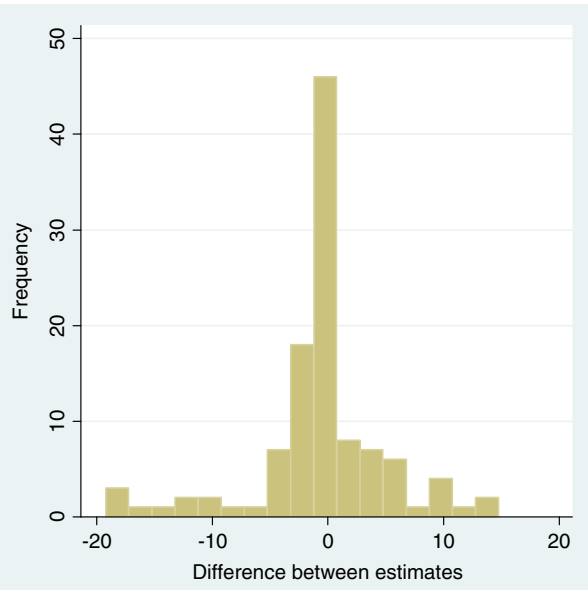

Note: The figure reports poverty headcounts estimated from 2014 and 2015 versions of PovcalNet data. In one case, they are estimated using the 2005 PPPs and in the other, 2011 PPPs.

Fig. 2 Country-level changes to poverty estimates

Figure 2 (Panel A) compares the latest country-level poverty estimates based on the $\$ 1.25$ line and 2005 PPPs with the corresponding estimate using the \$1.90 line and 2011 PPPs. Deviations from the 45-degree line reveal the difference in poverty between the estimates. Generally, there is a strong bivariate correlation between the estimates. The distribution of the differences in the poverty estimates gives a sense of the degree of changes across all countries. Figure 2 (Panel B) summarizes such changes across these poverty estimates, illustrating how the changes are concentrated close to zero, but with some clear outliers where changes are large. Some of these changes are considerable, while for the majority, the changes to country-level estimates are less jarring. ${ }^{41}$ The distribution of the absolute differences in the estimates suggests that for more than half the estimates, the change is smaller than 2 percentage points, while for three-quarters of the estimates in the poverty headcount changes by five percentage points or less. For about $10 \%$ of the countries, this change is greater than 8 percentage points. Some of the largest changes come in countries that either used imputed (regression-based) 2005 PPPs and who only participated in the 2011 ICP, or where there has been considerable revisions in underlying consumption aggregates.

\subsection{The regional poverty profile with the 2011 PPPs}

Globally, we estimate that 897 million people, or $12.7 \%$ of the world population, live in extreme poverty in 2012 under the $\$ 1.90$ poverty line at 2011 PPPs. The highest regional poverty rate is in Sub-Saharan Africa, where $42.7 \%$ of the population is estimated to live below the extreme poverty line, followed by South Asia (18.8\%) and East Asia (7.2\%). Table 5 summarizes the global and regional poverty measures (\% poor, depth of poverty and number of poor) for a selection of reference years between 1990 and $2012 .{ }^{42}$ In contrast to

\footnotetext{
${ }^{41}$ With the caveat that absolute and proportional changes are, of course, different.

${ }^{42} \mathrm{~A}$ more complete set of estimates will be available in PovcalNet in due course.
} 
Table 5 Global poverty by region, 1990-2012

\begin{tabular}{|c|c|c|c|c|c|c|c|c|}
\hline \multirow{2}{*}{$\begin{array}{l}\text { (a) Poverty headcount rate (\%) } \\
\text { Poverty line }\end{array}$} & \multicolumn{2}{|l|}{1990} & \multicolumn{2}{|l|}{1999} & \multicolumn{2}{|l|}{2011} & \multicolumn{2}{|l|}{2012} \\
\hline & $\$ 1.25$ & $\$ 1.90$ & $\$ 1.25$ & $\$ 1.90$ & $\$ 1.25$ & $\$ 1.90$ & $\$ 1.25$ & $\$ 1.90$ \\
\hline & 2005 & 2011 & 2005 & 2011 & 2005 & 2011 & 2005 & 2011 \\
\hline East Asia and Pacific & 57.0 & 60.6 & 35.9 & 37.5 & 7.9 & 8.5 & - & 7.2 \\
\hline Europe and Central Asia & 1.5 & 1.9 & 3.8 & 7.8 & 0.5 & 2.4 & - & 2.1 \\
\hline Latin America and the Caribbean & 12.6 & 17.8 & 11.0 & 13.9 & 4.6 & 5.9 & - & 5.6 \\
\hline Middle East and North Africa & 5.8 & 6.0 & 4.8 & 4.2 & 1.7 & - & - & - \\
\hline South Asia & 54.1 & 50.6 & 45.0 & - & 24.5 & 22.2 & - & 18.8 \\
\hline Sub-Saharan Africa & 56.8 & 56.8 & 59.4 & 58.0 & 46.9 & 44.4 & - & 42.7 \\
\hline World & 36.5 & 37.1 & 29.1 & 29.1 & 14.5 & 14.1 & - & 12.7 \\
\hline \multicolumn{9}{|l|}{ (b) Poverty gap (\%) } \\
\hline East Asia and Pacific & 19.5 & 21.5 & 10.8 & 11.6 & 1.6 & 1.8 & - & 1.5 \\
\hline Europe and Central Asia & 0.4 & 0.6 & 1.0 & 2.5 & 0.1 & 0.7 & - & 0.6 \\
\hline Latin America and the Caribbean & 5.2 & 8.6 & 4.8 & 6.0 & 2.2 & 2.8 & - & 2.6 \\
\hline Middle East and North Africa & 1.1 & 1.2 & 0.9 & 0.8 & 0.4 & - & - & - \\
\hline South Asia & 16.3 & 14.8 & 12.1 & - & 5.2 & 4.6 & - & 3.7 \\
\hline Sub-Saharan Africa & 25.5 & 24.9 & 26.6 & 26.4 & 19.2 & 17.3 & - & 16.5 \\
\hline World & 12.6 & 13.1 & 9.5 & 9.6 & 4.3 & 4.1 & - & 3.7 \\
\hline \multicolumn{9}{|l|}{ (c) Number of poor (million) } \\
\hline East Asia and Pacific & 939.1 & 995.5 & 661.3 & 689.4 & 160.8 & 173.1 & - & 147.2 \\
\hline Europe and Central Asia & 7.2 & 8.8 & 18.0 & 36.8 & 2.4 & 11.4 & - & 10.1 \\
\hline Latin America and the Caribbean & 55.1 & 78.2 & 55.5 & 71.1 & 27.6 & 35.3 & - & 33.7 \\
\hline Middle East and North Africa & 13.0 & 13.5 & 13.0 & 11.3 & 5.6 & - & - & - \\
\hline South Asia & 620.5 & 574.6 & 617.4 & - & 399.0 & 361.7 & - & 309.2 \\
\hline Sub-Saharan Africa & 291.0 & 287.6 & 385.8 & 374.6 & 415.8 & 393.6 & - & 388.8 \\
\hline World & 1925.7 & 1958.6 & 1751.2 & 1751.5 & 1011.4 & 983.3 & - & 896.7 \\
\hline
\end{tabular}

Note: Estimates from PovcalNet. 2005 PPP numbers from PovcalNet (2014 Update); 2011 PPP numbers from PovcalNet (2015 Update). See http://iresearch.worldbank.org/PovcalNet/ and http://iresearch.worldbank.org/ PovcalNetPPP2005/ for latest data and results

some of the large country-level revisions, the regional poverty profile based on the $\$ 1.90$ poverty line and 2011 PPPs largely maintains the picture of global poverty based on the $\$ 1.25$ line and 2005 PPPs.

The global count of poor with the new data is very similar to the global count based on the $\$ 1.25$ line and the 2005 PPPs. For 2011, the most recent year for which we have estimates for both the $\$ 1.90$ and $\$ 1.25$ lines, the global poverty headcount rate is $14.1 \%$ using the 2011 PPPs, compared to $14.5 \%$ with the 2005 PPPs. The difference in the number of poor is 28 million people. It is important to note that the aggregate global distribution is extremely dense around the current and past poverty lines. Edward and Sumner (2015) show that moving the poverty line by as little as 10 cents would move the count of global poor by more than 100 million. The high density of the distribution around the poverty line has also been an important aspect contributing to the rapid decline in poverty in recent years, such 
as the estimated reduction of number of poor by more than 80 million people between 2011 and 2012.

Although the global number of poor remains similar in the revised numbers, some of the regional changes are more significant. In the East Asia and the Pacific region, poverty in 2011 increases from $7.9 \%$ under the previous estimates based on the $\$ 1.25$ line to $8.5 \%$ in the new estimates using the $\$ 1.90$ line. This increase is largely driven by an upward adjustment of the poverty headcount rate in China, as a result of the new PPPs and new rural-urban price adjustments. The new estimates lower the aggregate poverty rate in SubSaharan Africa and South Asia by around 2 percentage points in the most recent update, to $44.4 \%$ and $22.2 \%$, respectively. ${ }^{43}$ In the Latin America and Caribbean region, and in Europe and Central Asia, poverty estimates are revised up with the 2011 PPPs, reflecting the lower upward adjustment in the PPP-adjusted welfare measures in these regions compared to the rise in the global poverty line. While the absolute change to overall poverty rates in these regions appears small at the $\$ 1.90$ line, the changes are more evident at higher poverty lines. As discussed, because of limited coverage, we do not report regional numbers for the MENA region at this time, although they are used in calculating the global average. ${ }^{44}$

\subsection{Past progress and future prospects for ending poverty}

The estimates for selected reference years using both the \$1.25 line and \$1.90 lines from 1990 until 2011, shown in Table 5, paint a very similar picture regarding the evolution of global and regional poverty. Global poverty has declined rapidly from 1990 until 2012, driven by a particularly strong decline in East and South Asia. Under both the previous and the updated poverty estimates, the first Millennium Development Goal of halving the share of the world population that live in extreme poverty between 1990 and 2015 was reached well ahead of time. In fact, our most recent estimate for 2012 of a $12.7 \%$ global headcount corresponds to a reduction in the global poverty rate by nearly two-thirds compared to $1990 .^{45}$ In absolute terms, the global number of poor has fallen by more than half, from more than 1.96 billion people in 1990 to 897 million in 2012. As Table 5 indicates, regional levels and trends are also broadly maintained under the new update.

Given the broad correspondence of the present and past global poverty profile under the two lines, it is not surprising that projections for the future also show a similar trajectory. We report on two (evidently speculative, and intended merely as illustrative) poverty scenarios for 2030, which are based on the country-specific historic average growth rates for the past 10 and 20 years. Depending on assumptions about average growth rates, projections for 2030 with the $\$ 1.90$ line suggests that there will be between 350 and 480 million poor

\footnotetext{
${ }^{43}$ For India, new PPPs and the revised spatial price adjustments work in opposite directions. Revised PPPs suggest that as a whole, India is richer than we used to think. Adjusting only for the new PPP, lowers the poverty rate nationally. Revised spatial adjustments (that are based on India's official poverty lines) suggest that the gap between urban and rural areas in the cost of living is half of what was implied in the earlier official poverty lines. Effectively, rural areas are not so much cheaper to live in than urban areas, as we used to think, and this tends to raise poverty. The net effect of the two adjustments is to lower poverty somewhat.

${ }^{44}$ Although the regional MENA numbers and several country-level poverty estimates are not reported due to low coverage and concerns with the aggregates, poverty estimates for these countries (and the region as a whole) are calculated for the purposes of global poverty estimation.

${ }^{45}$ Because of lower survey coverage in the past, estimates for earlier reference years rely more heavily on interpolated and extrapolated surveys. For the 1990 estimate, the average 'length' of extrapolation/interpolation is 5.2 years ( 1.5 years population weighted), while for 2012 this is down to 2.4 years $(0.5$ years population weighted).
} 
people in 2030, which would yield a global poverty rate between $4.2 \%$ and $5.7 \%$, short of the World Bank target of less than $3 \%$, globally. ${ }^{46}$ These projections are slightly more optimistic than the similar projections with the $\$ 1.25$ line carried out in Jolliffe et al. (2014), which ranged from $4.8 \%$ to $6.8 \%$. The slightly more optimistic projections are due to a modestly lower starting point in 2011 , and also caused by a greater relative concentration of poverty in Asia under the new poverty line, where poverty is expected to fall relatively faster than other regions due to higher per capita growth. The projected profile of global poverty in 2030, shown in Figure A4 in the Online Appendix, suggests that the vast majority of poor people will live in Sub-Saharan Africa (more than $85 \%$ of the total) with projections using both lines. Broadly speaking, this analysis indicates that the goal of ending extreme poverty by 2030 will be very ambitious, especially for Sub-Saharan Africa.

\section{Conclusions}

The measurement of extreme income poverty for the world as a whole has attracted considerable interest over the last two and half decades. Reducing and, more recently, ending global poverty have become central components of the development objectives shared by the international community, as expressed in the Millennium Development Goals and, just this year, in the Sustainable Development Goals that succeed them.

Given the conceptual desirability of defining extreme poverty in terms of a common level of well-being across all countries, the measurement and monitoring of global poverty has typically been done with respect to a money-metric yardstick anchored on the poverty lines of very poor countries, and converted to other currencies using Purchasing Power Parity (PPP) exchange rates. One challenging consequence of this approach is that PPPs are themselves difficult to collect information for, and to construct. Major changes in the nature of PPPs have taken place at various points in time, including 1993, 2005 and, most recently, 2011. Each time the PPPs change, the international poverty line that builds on them changes too - although there usually is some discretion in how the change is implemented.

In addition to the poverty line, changes over time in the distributions of income and consumption for various countries also affect global poverty counts and measures. Most of these are of course the real changes in living standards that we wish to monitor. But, in addition, new countries are added that were previously not included and, more rarely, countries previously included, drop out. Price indices used to compare incomes over time are revised. Spatial cost-of-living adjustments made to enhance the comparability of living standards between urban and rural areas - or across different regions of large countries change as well.

This paper documents as extensively as possible the various changes in all of these domains, which were used in constructing a new global count of the extremely income poor for the year 2012, using the new 2011 PPPs. This global count underpins the World Bank's recent poverty update in Cruz et al. (2015) and World Bank (2015a), and is based on a new international poverty line set at $\$ 1.90$ a day (per capita) in 2011 PPPs. This line was derived in accordance with our best judgment of how to maintain the real value of the $\$ 1.25$ line (at 2005 PPPs) in poor countries, so as to preserve the integrity of the "goalposts" for international targets such as the SDGs and the World Bank's own goals. Specifically, the values of the fifteen poverty lines that underpinned the $\$ 1.25$ line were taken in local currency

\footnotetext{
${ }^{46}$ The growth rates assumed in the projections are country-specific 10 year and 20 year historic growth rates.
} 
units in 2005, and inflated to 2011 prices using the best available domestic price or costof-living indices. The resulting values were converted to USD using 2011 PPPs. A simple average of these numbers yielded $\$ 1.88$, which we rounded to $\$ 1.90$. A number of alternative approaches - including taking the local currency lines corresponding to $\$ 1.25$ (in 2005 PPPs) in 101 developing countries, inflating them to 2011 using domestic CPIs, and then converting them to USD with the 2011 PPPs - yield results that are either exactly equal to $\$ 1.90$, or very close.

In addition to changes in the line, we have documented in some detail which price indices were used for each of the 133 countries included in the exercise, with particular emphasis on those where the number differs from the indices reported in the World Development Indicators. We have also discussed those cases where adjustments are made to consumption or income vectors to account for spatial differences in the cost of living within countries, including China, India, Indonesia and countries in Latin America, the Caribbean, Europe and Central Asia.

The combined result of these various changes for the year 2011 is that the global headcount rate changes from $14.5 \%$ (with respect to the $\$ 1.25$ line, at 2005 PPPs) to $14.1 \%$ (with respect to the $\$ 1.90$ line, at 2011 PPPs). This change corresponds to 28 million people. For 2012, the reference year for the new count, the incidence is $12.7 \%$, corresponding to 897 million persons. The regional profile of poverty changes only moderately, with the new method yielding slightly lower poverty in the poorest regions (notably Sub-Saharan Africa and South Asia), and slightly higher poverty in middle-income regions (notably Latin America and the Caribbean, and Europe and Central Asia). Trends over time between 1990 and 2012 are very similar using the new and old methods, and projections of possible future poverty trajectories under the assumption of distribution neutral growth are similarly little affected.

The fact that this update yields relatively limited changes to what we thought we knew about global poverty is a result of the fact that these methodological revisions were deliberately designed so as to preserve the real purchasing power of the $\$ 1.25$ line in some of the world's poorest countries - and of the additional fact that, between 2005 and 2011, price level changes in these countries were not atypical of the developing world as a whole. That the line is much higher in USD terms is simply a reflection of the fact that the 2011 ICP price surveys found lower price levels (and thus a higher purchasing power) in poor countries relative to the US, compared to the 2005 PPPs. The 2011 PPPs thus incorporate a lower relative purchasing power of the USD.

The exercise of updating the international poverty line when PPPs change - and the associated process of reviewing temporal and spatial price adjustments in over one hundred countries - is complex. Transparency and replicability are essential to ensure credibility, and we believe that this paper is a step in that direction. Even more importantly, the PovcalNet online tool will soon include the updated distributions, poverty line and PPP options to enable other researchers to replicate our results, as well as making different choices of their own.

Looking forward, we feel that one area where additional research is particularly needed, in order to enhance international comparability, is that of spatial cost-of-living adjustments. These are still made in a piecemeal and uncoordinated fashion across regions. While we feel that each of the adjustments we have made here is defensible in its own right, their consistency across space and time requires additional scrutiny. In that matter, and in many others, we look forward to advice from the Global Commission on Poverty, led by Professor Sir Anthony Atkinson, which was recently convened to advise the World Bank on how to take global poverty measurement forward, after this 2012 update. 
Acknowledgments This paper benefited from the efforts of numerous World Bank colleagues, including in the PovcalNet team (Qinghua Zhao, Kihoon Lee and Liang Yu) and the Global Poverty Working Group (in particular Rose Mungai, Raul Andres Castaneda, Leonardo Lucchetti, Lilliana de Sousa, Minh Nguyen, Joao Pedro de Azevedo, Jose Montes, Reno Dewina, Carolina Diaz Bonilla, Monica Yanez Pagans, Hiroki Uematsu and Christina Wieser). The authors would also like to thank Kaushik Basu for his guidance; the editors of this special issue, Nora Lustig and Jacques Silber; as well as Aziz Atamanov, Marcio Cruz, Angus Deaton, Stephan Klasen, Nandini Krishnan, Christoph Lakner, Rinku Murgai, Sergio Olivieri, Martin Ravallion, Don Sillers and Philip Schellekens for comments and helpful conversations. That said, these are the views of the authors alone, and we are solely responsible for any remaining errors.

Open Access This article is distributed under the terms of the Creative Commons Attribution 4.0 International License (http://creativecommons.org/licenses/by/4.0/), which permits unrestricted use, distribution, and reproduction in any medium, provided you give appropriate credit to the original author(s) and the source, provide a link to the Creative Commons license, and indicate if changes were made.

\section{References}

Ahluwalia, M., Carter, N., Chenery, H.: Growth and poverty in developing countries. J. Dev. Econ. 6(3), 299-341 (1979)

Asian Development Bank: Purchasing power parities and real expenditures. Mandaluyong City, Philippines: Asian Development Bank. www.adb.org/sites/default/files/publication/59715/ 2011-icp-ppps-real-expenditures.pdf (2014)

Balassa, B.: The PPP doctrine: a reappraisal. J. Polit. Econ. 72, 584-596 (1964)

Bamberger, M., Rugh, J., Mabry, L.: Real World Evaluation: Working under Budget, Time, Data, and Political Constraints. Sage Publications, Thousand Oaks (2006)

Beegle, K., De Weerdt, J., Friedman, J., Gibson, J.: Methods of household consumption measurement through surveys: experimental results from Tanzania. J. Dev. Econ. 98(1), 3-18 (2012)

Biemer, P., Lyberg, L.: Introduction to Survey Quality. Wiley Series in Survey Methodology. Wiley, Hoboken (2003). search.ebscohost.com/login. aspx ?direct $=$ true $\&$ scope $=$ site $\& d b=$ lebk $\& d b=$ nlabk $\& A N=85511$

Buhmann, B., Rainwater, L., Schmaus, G., Smeeding, T.: Equivalence scales, well-being, inequality and poverty: sensitivity estimates across ten countries using the Luxembourg Income Study (LIS) database. Rev. Income Wealth 34(3), 115-142 (1988)

CEDLAS and World Bank: A Guide to the SEDLAC: Socioeconomic Database for Latin America and the Caribbean. CEDLAS and The World Bank. sedlac.econo.unlp.edu.ar/download.php?file=archivos upload_items_metodologia/Guide_14_english.pdf (2010)

Chandy, L., Kharas, H.: The poverty of poverty data: Brookings Institution blog, http://www.brookings.edu/ blogs/up-front/posts/2014/10/10-global-poverty-data-chandy-kharas (2014)

Chandy, L., Smith, C.: How poor are America's poorest? U.S. \$2 a day poverty in a global context. Global Economy and Development, Global Views, Policy Paper 2014-03. Brookings Institution, Washington (2014). www.brookings.edu/ /media/research/files/papers/2014/08/ america-poverty-global-context/how-poor-are-americas-poorest.pdf

Chen, S., Ravallion, M.: How well did the world's poorest fare in the 1990s? Rev. Income Wealth 47(3), 283-300 (2001)

Chen, S., Ravallion, M.: How have the world's poorest fared since the early 1980s? World Bank Res. Obs. 19(2), 141-169 (2004)

Chen, S., Ravallion, M.: China is poorer than we thought, but no less successful in the fight against poverty. World Bank Policy Research Working Paper, No. 4621. openknowledge.worldbank.org/handle/10986/ 6674 (2008)

Chen, S., Ravallion, M.: The developing world is poorer than we thought, but no less successful in the fight against poverty. Q. J. Econ. 125(4), 1577-1625 (2010)

Cruz, M., Foster, J., Quillin, B., Schellekens, P.: Ending extreme poverty and sharing prosperity: progress and policies. Policy Research Note PRN/15/03 (2015)

Datt, G.: Computational tools for poverty measurement and analysis. International Food Policy Research Institute, Food Consumption and Nutrition Division Discussion Paper No. 50. ideas.repec.org/p/fpr/fcnddp/50.html (1998)

Deaton, A.: Price indexes, inequality, and the measurement of world poverty. Am. Econ. Rev. 100(1), 5-34 (2010) 
Deaton, A., Aten, B.: Trying to understand the PPPs in ICP2011: why are the results so different? NBER Working Paper No 20244. www.nber.org/papers/w20244 (2014)

Deaton, A., Kozel, V.: Data and Dogma: The great Indian poverty debate. World Bank Res. Obs. 20(2), 177-99 (2005a)

Deaton, A., Kozel, V. (eds.): The Great Indian Poverty Debate. Macmillan India Ltd, New Delhi (2005b)

Dykstra, S., Kenny, C., Sandefur, J.: Global absolute poverty fell by almost half on Tuesday. Centre for Global Development blog: www.cgdev.org/blog/global-absolute-poverty-fell-almost-half-tuesday (2014)

Edward, P., Sumner, A.: New estimates of global poverty and inequality: how much difference do price data really make? CGD Working Paper no. 403, Washington, DC: Center for Global Development. www.cgdev.org/sites/default/files/CGD-Working-Paper-403-Edward-Sumner-New-Estimates-Global-Poverty.pdf (2015)

Gimenez, L., Jolliffe, D.: Inflation for the poor: a comparison of CPI and household survey data. Bangladesh Development Studies 37(1/2), 57-81 (2014)

Government of India: Report of the Task Force on Projections of Minimum Needs and Effective Consumption. Planning Commission, New Delhi (1979)

Government of India: Report of the Expert Group to Review the Methodology for Estimation of Poverty. Planning Commission, New Delhi (2009). planningcommission.gov.in/reports/genrep/rep_pov.pdf

Government of India: Press Note on Poverty Estimates, 2011-12. Planning Commission, New Delhi (2013)

Inklaar, R., Rao, D.S.: Cross-country income levels over time: did the developing world suddenly become much richer? GGDC Research Memorandum Working Paper no. 151. www.ggdc.net/publications/ memorandum/gd151.pdf (2014)

James, W., Schofield, E.: Human Energy Requirements. A Manual for Planners and Nutritionists. Oxford Medical Publications, Oxford (1990)

Jolliffe, D.: Measuring absolute and relative poverty: the sensitivity of estimated household consumption to survey design. J. Econ. Soc. Meas. 27(1-2), 1-23 (2001)

Jolliffe, D.: Poverty, prices and place: how sensitive is the spatial distribution of poverty to cost of living adjustments? Econ. Inq. 44(2), 296-310 (2006)

Jolliffe, D., Lanjouw, P., Chen, S., Kraay, A., Meyer, C., Negre, M., Prydz, E., Vakis, R., Wethli, K.: A Measured Approach to Ending Poverty and Boosting Shared Prosperity: Concepts, Data, and the Twin Goals. Policy Research Report. The World Bank, Washington (2014)

Jolliffe, D., Prydz, E.B.: Global poverty goals and prices: how purchasing power parity matters. Policy Research Working Paper, No. 7256. The World Bank, Washington (2015)

Jolliffe, D., Prydz, E.B.: Estimating international poverty lines from comparable national thresholds: a robust approach for estimating relevant thresholds. Journal of Economic Inequality, this issue (2016)

Kakwani, N.: On a class of poverty measures. Econometrica 48, 437-446 (1980)

Kakwani, N., Son, H.: Global poverty estimates based on 2011 purchasing power parity: where should the new poverty line be drawn? ECINEQ Working Paper, pp. 2015-371 (2015)

Klasen, S., Krivobokova, T., Greb, F., Lahoti, R., Pasaribu, S., Wiesenfarth, M.: International income poverty measurement: which way now? Journal of Economic Inequality, this issue (2016)

Kravis, I., Summers, R., Heston, A.: Real GDP per capita for more than one hundred countries. Econ. J. 88(8), 215-242 (1978)

Lakner, C., Negre, M., Prydz, E.B.: The role of inclusive growth in ending extreme poverty. paper presented at Sixth ECINEQ Meeting, July 2015 (2015)

Lanjouw, P., Ravallion, M.: Poverty and household size. Econ. J. 105(433), 1415-1434 (1995)

Minoiu, C., Reddy, S.: Estimating poverty and inequality from grouped data: how well do parametric methods perform? Journal of Income Distribution 18(2), 160-78 (2009)

Ravallion, M.: Measuring aggregate welfare in developing countries: how well do national accounts and surveys agree? Rev. Econ. Stat. 85(3), 645-652 (2003)

Ravallion, M.: A global perspective on poverty in India. Econ. Polit. Wkly. 43(43), 31-37 (2008). www.jstor. org/stable/40278099

Ravallion, M.: Price levels and economic growth: making sense of revisions to data on real incomes. Rev. Income Wealth 59(4), 593-613 (2013)

Ravallion, M.: An exploration of the international comparison program's new global economic landscape. NBER Working Paper No 20338 www.nber.org/papers/w20338 (2014)

Ravallion, M., Chen, C., Sangraula, P.: Dollar a day revisited. World Bank Econ. Rev. 23(2), 163-184 (2009)

Ravallion, M., Datt, G., Walle, D.: Quantifying absolute poverty in the developing world. Rev. Income Wealth 37(4), 345-361 (1991)

Reddy, S., Pogge, T.: How not to count the poor. In: Anand, S., Segal, P., Stiglitz, J. (eds.) Debates on the Measurement of Poverty. Oxford University Press (2008)

Sandefur, J.: Africa rising? Using micro surveys to correct macro time series. Center for Global Development, manuscript editorialexpress.com/cgi-bin/conference/download.cgi?db_name=NEUDC2013\& paper_id=457 (2013) 
Samuelson, P.: Theoretical notes on trade problems. Rev. Econ. Stat. 46, 145-154 (1964)

Serajuddin, U., Uematsu, H., Wieser, C., Yoshida, N., Dabalen, A.: Data deprivation: another deprivation to end. Policy Research Working Paper, No. 7252. World Bank, Washington (2015)

Sillers, D.: Is $\$ 1.82$ the new $\$ 1.25$ ? Choosing the next international extreme poverty line. USAID Economic Brief July. USAID, Washington (2015)

Smith, L., Dupriez, O., Troubat, N.: Assessment of the reliability and relevance of the food data collected in national household consumption and expenditure surveys. International Household Survey Network, Food and Agriculture Organization of the United Nations and World Bank. www.ihsn.org/home/sites/ default/files/resources/HCES\%20food\%20data\%20assessment\%20report_DRAFT_V8_25_02_14.pdf (2014)

Statistics Indonesia: Number Of Poor People, Percentage of Poor People and The Poverty Line, 1970-2013'. Jakarta: Government of Indonesia, www.bps.go.id/linkTabelStatis/view/id/1494 (2015)

United Nations Statistics Division: Handbook on Poverty Statistics: Concepts, Methods and Policy Use. New York, NY: United Nations unstats.un.org/unsd/methods/poverty/pdf/un_book\%20final\%2030\%20dec \%2005.pdf (2005)

Villasenor, J., Arnold, B.: Elliptical Lorenz curves. J. Econ. 40(2), 327-338 (1989)

World Bank: World Development Report: Poverty. The World Bank, Washington (1990)

World Bank: Tajikistan: Poverty Assessment. The World Bank, Washington (2009). openknowledge. worldbank.org/handle/10986/3159

World Bank: Bangladesh Poverty Assessment: Assessing a decade of progress in reducing poverty, 20002010. Bangladesh Development Series, The World Bank, Dhaka. www.worldbank.org/en/news/feature/ 2013/06/20/bangladesh-poverty-assessment-a-decade-of-progress-in-reducing-poverty-2000-2010 (2013)

World Bank: Purchasing Power Parities and the Real Size of World Economies: A Comprehensive Report of the 2011 International Comparison Program. The World Bank, Washington (2015a)

World Bank: Global Monitoring Report 2015/2016: Development in an Era of Demographic Change. The World Bank, Washington (2015b)

World Bank: Technical note on latest Ghana's poverty figures GLSS round 6: 2012-2013. Ghana Poverty Assessment 2012/13. Manuscript, forthcoming (2015c) 